\title{
The influence of organic compounds on the development of precipitation acidity in maritime clouds
}

\author{
L. Alfonso and G. B. Raga \\ Centro de Ciencias de la Atmósfera, UNAM, 04510 Mexico City, Mexico \\ Received: 21 November 2003 - Published in Atmos. Chem. Phys. Discuss.: 26 January 2004 \\ Revised: 25 June 2004 - Accepted: 29 June 2004 - Published: 9 July 2004
}

\begin{abstract}
In order to estimate the anthropogenic influence of gas and aerosol emissions from the Petroleum Industry in maritime zones with clouds of small vertical extent, a numerical 1-D Eulerian cloud-chemical model with detailed microphysics (Alfonso and Raga, 2002) is used to simulate the influence of water soluble organic compounds (WSOC) and organic+inorganic gas emissions on cloud development. Following Mircea et al. (2002), we tested the sensitivity of the cloud and precipitation development in the classical inorganic case (CIC) and the inorganic+organic case (IOC) with respect to $\mathrm{CCN}$ compositions. The results indicate an increase in the droplet concentration for the IOC, and a delay in the development of precipitation.

The $\mathrm{pH}$ spectral evolution was studied during both the development and precipitation stages. The influence of the diffusion of formic acid and its generation by oxidation of hydrated formaldehyde in the aqueous phase result in a reduction in the $\mathrm{pH}$ of precipitation in the range between 0.05 and $0.15 \mathrm{pH}$ units (from 1 to $3 \%$ ) for the high ambient $\mathrm{SO}_{2}$ concentration $(20 \mathrm{ppb}$ ) and between $0.2-0.5 \mathrm{pH}$ units (from 4 to $10 \%$ ) for the low ambient $\mathrm{SO}_{2}$ concentration (1 ppb) case.
\end{abstract}

\section{Introduction}

It has been known for many years that radically different cloud condensation nuclei (CCN) size distributions and compositions, play a clear role in precipitation development. Even though a large number of efforts have been conducted to address this subject, the role of organic compounds in the microphysical and dynamical structure of clouds remains unclear. Within the present discussion on climate change, the role of organic carbon has gained more attention. A number of attemps to obtain a mass balance of organic carbon (OC)

Correspondence to: L. Alfonso

(lesterson@yahoo.com) in the aerosols have been carried out, but no available identification of individual compounds has been possible so far (Saxena and Hildemann, 1996).

Likens et al. (1983) studied the potential role of organic compounds in the chemistry of wet aerosols many years ago. Recently, the contribution of organic aerosols to the mass of cloud condensation nuclei (CCN) has been brought back as an unresolved topic (Novakov and Penner, 1993; Corrigan and Novakov, 1999). They reported that pure organic smoke aerosols from cellulose combustion are efficient CCN without being associated to inorganic salts.

Sources of monocarboxylic acids in gases, aerosols and cloud droplets comprise anthropogenic and biogenic emissions and chemical transformations of precursors, while dicarboxylic acids are likely to be found principally in aerosol from primary sources. Various sources of organic acids in the atmosphere were mentioned by Chebbi and Carlier (1996) including: plastic combustions, tobacco smoke, chemical plant transformations, refuse incineration factories, biomass burning, motor vehicle exhausts and aqueous phase reactions in drops (Yao et al., 2002).

Formic, acetic and other lightweight carboxylic acids, formaldehyde and other gas phase derived species were reported by Facchini et al. (1999) to constitute dissolved organic compounds. Löflund et al. (2002) and Hegg et al. (2002) measured concentrations of carboxylic and dicarboxylic acids in continental and maritime cloud water. Low weight dicarboxylic acids are hygroscopic and have recently received much attention because of their potential effects in cloud formation (Cruz and Pandis, 1997). Another important question is the formation of organic films on the surface of droplets. Organic films may be common in water droplets and may retard evaporation and condensation. The possible implications for cloud spectral broadening were recently reported by Feingold and Chuang (2002). 
In our paper we explore the role of water soluble organic compounds and estimate the impact of emissions on cloud development. A very important question is the influence of the $\mathrm{SO}_{2}$ and hydrocarbon emissions from Petroleum Industry in the Campeche area of Mexico, where numerous marine platforms are located. The main offshore petroleum extracting areas are found in the southern end of the Gulf of Mexico, and in the vicinity of the states of Veracruz, Tabasco and Campeche in Mexico.

We present results from a theoretical 1-D cloud model that includes detailed microphysics and organic and inorganic chemistry. The main two goals of our investigation are:

1. To study the influence of water- soluble organic compounds (WSOC) on CCN activation and droplet concentration.

2. To study the impact of chemical reactions both inorganic and simple organics to attempt to estimate their impact on precipitation acidification.

The role of water soluble organic compounds (WSOC) in the $\mathrm{pH}$ spectra of precipitation, is beyond the scope of the study and was not included in the analysis.

\section{The cloud chemistry model}

\subsection{Microphysics}

The model microphysics follows Alfonso and Raga (2002) (hereafter denoted as AR2002) and includes the following microphysical processes: nucleation of $\mathrm{CCN}$, condensation and evaporation, collision and coalescence, and breakup. The cloud and CCN spectra are discretized using the method described by Berry (1967). For CCN composition, we consider two cases: the classical inorganic case (CIC), assuming that $\mathrm{CCN}$ are composed only by inorganic compounds and the inorganic + organic case (IOC), when CCN composition includes inorganic and WSOC, as discussed in more detailed in Sect. 2.3.1. The procedures for calculating activation, condensation, coalescence and breakup are described in AR2002.

In our model we have 64 bins for the entire $\mathrm{CCN}$ spectrum (from 0.0041 to $5.93 \mu \mathrm{m}$ ), 48 bins for the small droplets (from 0.0041 to $1 \mu \mathrm{m}$ ) and 73 bins for the rest of the droplet spectrum (from 1 to $4096 \mu \mathrm{m}$ ). Therefore, we could have droplets smaller that $1 \mu \mathrm{m}$ after the activation of $\mathrm{CCN}$. Within our formalism, these small droplets are immediately transferred to the small droplets grid.

Without this additional grid, there would be a need to extrapolate these droplets onto the grid for the rest of the spectrum (from 1 to $4096 \mu \mathrm{m}$ ), and, as a result, there would be an artifficial peak in the smaller bin (for $1 \mu \mathrm{m}$ ). By doing this, we avoided an artifficial accumulation of activated droplets in the smaller bin, droplets that are actually smaller than
$1 \mu \mathrm{m}$. On the other hand, interpolation methods are very diffusive and result in an artifficial broadening of the aerosol and droplet spectra. By doing this, the artificial increase in droplet concentration at the small end of the spectrum (for droplets larger than $1 \mu \mathrm{m}$ ) observed in some models is avoided. There is no evolution by coalescence and breakup for these small droplets.

\subsection{Dynamics}

As discussed in AR2002, the model dynamics is based on the one-dimensional framework developed by Asai and Kasahara (1967), where a cylindrical cloud of constant radius develops in an environment at rest. All equations are expressed in terms of cylindrical coordinates and cloud variables are represented by mean values averaged over the horizontal cross section of the cloud.

The dynamic equations are solved for the vertical air velocity, $w$; radial air velocity, $u_{a}$; temperature, $T$; water vapor mixing ratio, $Q_{v}$; for cloud condensation nuclei $(\mathrm{CCN})$ number density in category $i,(f(i))$, with a maximum of 64 categories from 0.0041 to $5.93 \mu \mathrm{m}$; for cloud number density function for small droplets in category $j, f_{d s}(j)$, with a maximum of 48 categories from 0.0041 to $1 \mu \mathrm{m}$; for cloud number density function for large drops in category $j, f_{d}(j)$, with a maximum of 73 categories from 1 to $4096 \mu \mathrm{m}$; for the mass density functions of particles in small droplets and drops in category $j,\left(g_{d s}(j), g_{d}(j)\right)$; for the mass density function of chemical species for small droplets and drops in category $j,\left(g_{d s C}(j), g_{d C}(j)\right)$; and for the concentration of gases $\left(C_{g}\right)$ in the air.

Dynamic equations for vertical air velocity, $w$; radial air velocity, $u_{a}$; temperature, $T$; water vapor mixing ratio, $Q_{v}$ are described in detail in Alfonso et al. (1998) and AR2002. We assumed for every variable $A$ (Ogura and Takahashi, 1971) that

$A_{a}=A_{e}$ if $u_{a}<0$

$A_{a}=A$ if $u_{a}>0$

here $A_{e}$ denotes environmental parameters, while $A_{a}$ refers to values at the perimeter of the cloud, and $A$ refers to values inside the cloud. The distribution functions are calculated through the following equations, and a description of each term is given immediately following the equations.

The evolution of the CCN number density, $f(i)$, for every category $i$ (from 0.0041 to $5.98 \mu \mathrm{m}, 64$ categories) is calculated as:

$$
\begin{aligned}
& \frac{\partial f(i)}{\partial t}=-w \frac{\partial f(i)}{\partial z}-2 \frac{\alpha^{2}}{a}|w|\left[f(i)-f_{e}(i)\right] \\
& +\frac{2}{a} u_{a}\left[f(i)-f_{a}(i)\right]+\frac{1}{\rho_{a}} \frac{\partial}{\partial z}\left(\rho_{a} K \frac{\partial f(i)}{\partial z}\right)+\left(\frac{\partial f(i)}{\partial t}\right)_{a c t}
\end{aligned}
$$

where the term $(\partial / \partial \mathrm{t})_{a c t}$ corresponds to the activation of CCN. Two distributions are calculated, $f(i)_{C I C}$ and 
$f(i)_{I O C}$ for the classical inorganic $\left(\left(\mathrm{NH}_{4}\right)_{2} \mathrm{SO}_{4}\right)$ and the inorganic+organic $\left(\left(\mathrm{NH}_{4}\right)_{2} \mathrm{SO}_{4}+\mathrm{WSOC}\right)$ cases respectively. In all the equations, the variables with subscript $e$ denote environmental parameters, while subscript $a$ refers to values at the perimeter of the cloud, and $V_{r}$ corresponds to the terminal velocity of drops. The first term on the right-hand side of each equation represents the vertical advection, the second term is the lateral eddy exchange, which is often called turbulent entrainment through the lateral boundary of the cloud, the third term is the effect of divergence of terminal velocities of raindrops, the fourth term is the dynamic entrainment term required to satisfy the mass continuity and the fifth term is the vertical turbulent diffusion. The terms $(\partial / \partial \mathrm{t})_{a c t}$, $(\partial / \partial \mathrm{t})_{C E},(\partial / \partial \mathrm{t})_{c o a l},(\partial / \partial \mathrm{t})_{B},(\partial / \partial \mathrm{t})_{d i f f}$ and $(\partial / \partial \mathrm{t})_{a q}$ represent the effects of nucleation, condensation and evaporation, coalescence, breakup, gas uptake and aqueous phase reactions respectively. In the equations for aerosols and small droplets, we did not include the third term (effect of divergence due to terminal velocity).

The time evolution of the cloud number density functions for small droplets, $f_{d s}(j)$, for each category, from 0.0041 to $1 \mu \mathrm{m}$ (48 categories) is calculated according to:

$$
\begin{aligned}
& \frac{\partial f_{d s}(j)}{\partial t}=-w \frac{\partial f_{d s}(j)}{\partial z}-2 \frac{\alpha^{2}}{a}|w|\left[f_{d s}(j)-f_{d s e}(j)\right] \\
& +\frac{2}{a} u_{a}\left[f_{d s}(j)-f_{d s a}(j)\right]+\frac{1}{\rho_{a}} \frac{\partial}{\partial z}\left(\rho_{a} K \frac{\partial f_{d s}(j)}{\partial z}\right) \\
& +\left(\frac{\partial f_{d s}(j)}{\partial t}\right)_{a c t}+\left(\frac{\partial f_{d s}(j)}{\partial t}\right)_{C E}
\end{aligned}
$$

Now, not only the the activation term is present, but also a term $(\partial / \partial \mathrm{t})_{C E}$ that represents droplet growth by condensation or decrease by evaporation.

The cloud number density distribution function $\left(f_{d}(j)\right)$ for drops with radius between $1 \mu \mathrm{m}$ and $4096 \mu \mathrm{m}$ (73 categories) is calculated from:

$$
\begin{aligned}
& \frac{\partial f_{d}(j)}{\partial t}=-\left(w-V_{r}(j)\right) \frac{\partial f_{d}(j)}{\partial z}-2 \frac{\alpha^{2}}{a}|w|\left[f_{d}(j)-f_{d e}(j)\right] \\
& +\frac{f_{d}(j) V_{r}(j)}{\rho_{a}} \frac{\partial \rho_{a}}{\partial z}+\frac{2}{a} u_{a}\left[f_{d}(j)-f_{d a}(j)\right]+\frac{1}{\rho_{a}} \frac{\partial}{\partial z}\left(\rho_{a} K \frac{\partial f_{d}(j)}{\partial z}\right) \\
& \left(\frac{\partial f_{d}(j)}{\partial t}\right)_{a c t}+\left(\frac{\partial f_{d}(j)}{\partial t}\right)_{C E}+\left(\frac{\partial f_{d}(j)}{\partial t}\right)_{c o a l}+\left(\frac{\partial f_{d}(j)}{\partial t}\right)_{B}
\end{aligned}
$$

where the coalescence $(\partial / \partial \mathrm{t})_{\text {coal }}$, the breakup $(\partial / \partial \mathrm{t})_{B}$ terms, and the effect of terminal velocity for each category are now included.

The cloud mass density function of particles in the drops with radius between $1 \mu \mathrm{m}$ and $4096 \mu \mathrm{m}, g_{d}(j)$, is calculated from:

$$
\begin{aligned}
& \frac{\partial g_{d}(j)}{\partial t}=-\left(w-V_{r}(j)\right) \frac{\partial g_{d}(j)}{\partial z}-2 \frac{\alpha^{2}}{a}|w|\left[g_{d}(j)-g_{d e}(j)\right] \\
& +\frac{g_{d}(j) V_{r}(j)}{\rho_{a}} \frac{\partial \rho_{a}}{\partial z}+\frac{2}{a} u_{a}\left[g_{d}(j)-g_{d a}(j)\right]+\frac{1}{\rho_{a}} \frac{\partial}{\partial z}\left(\rho_{a} K \frac{\partial g_{d}(j)}{\partial z}\right)
\end{aligned}
$$

$$
\left(\frac{\partial g_{d}(j)}{\partial t}\right)_{a c t}+\left(\frac{\partial g_{d}(j)}{\partial t}\right)_{C E}+\left(\frac{\partial g_{d}(j)}{\partial t}\right)_{c o a l}+\left(\frac{\partial g_{d}(j)}{\partial t}\right)_{B}
$$

Two mass density distribution functions $g_{d C I C}(j)$, $g_{d s I O C}(j)$ are calculated for the classical inorganic $\left(\left(\mathrm{NH}_{4}\right)_{2} \mathrm{SO}_{4}\right)$ and inorganic+organic $\left(\left(\mathrm{NH}_{4}\right)_{2} \mathrm{SO}_{4}+\mathrm{WSOC}\right)$ $\mathrm{CCN}$ in the drops respectively.

The time evolution of the mass density distribution functions of particles in the small drops (radius between 0.0041 and $1 \mu \mathrm{m}), g_{d s}(j)$, is calculated for each category number $(j)$ according to:

$$
\begin{aligned}
& \frac{\partial g_{d s}(j)}{\partial t}=-w \frac{\partial g_{d s}(j)}{\partial z}-2 \frac{\alpha^{2}}{a}|w|\left[g_{d s}(j)-g_{d s e}(j)\right] \\
& +\frac{2}{a} u_{a}\left[g_{d s}(j)-g_{d s a}(j)\right]+\frac{1}{\rho_{a}} \frac{\partial}{\partial z}\left(\rho_{a} K \frac{\partial g_{d s}(j)}{\partial z}\right) \\
& \left(\frac{\partial g_{d s}(j)}{\partial t}\right)_{a c t}+\left(\frac{\partial g_{d s}(j)}{\partial t}\right)_{C E}
\end{aligned}
$$

where $g_{d s}(j)$ are the cloud mass density distribution functions $g_{d S C I C}(j), g_{d S I O C}(j)$ for the classical inorganic $\left(\left(\mathrm{NH}_{4}\right)_{2} \mathrm{SO}_{4}\right)$ and inorganic+organic $\left(\left(\mathrm{NH}_{4}\right)_{2} \mathrm{SO}_{4}+\mathrm{WSOC}\right)$ $\mathrm{CCN}$ in small drops. Note that in this equation, the coalescence, the breakup terms, and the effect of terminal velocity are not considered.

For drops with radius between 1 and $4096 \mu \mathrm{m}$, the time evolution for the mass density functions of chemical species $\left(g_{d C}(j)\right)$ is given by the equation:

$$
\begin{aligned}
& \frac{\partial g_{d C}(j)}{\partial t}=-\left(w-V_{r}(j)\right) \frac{\partial g_{d C}(j)}{\partial z}-2 \frac{\alpha^{2}}{a}|w|\left[g_{d C}(j)-g_{d C e}(j)\right] \\
& +\frac{g_{d C}(j) V_{r}(j)}{\rho_{a}} \frac{\partial \rho_{a}}{\partial z}+\frac{2}{a} u_{a}\left[g_{d C}(j)-g_{d C a}(j)\right]+\frac{1}{\rho_{a}} \frac{\partial}{\partial z}\left(\rho_{a} K \frac{\partial g_{d C}(j)}{\partial z}\right) \\
& +\left(\frac{\partial g_{d C}(j)}{\partial t}\right)_{a c t}+\left(\frac{\partial g_{d C}(j)}{\partial t}\right)_{C E}+\left(\frac{\partial g_{d C}(j)}{\partial t}\right)_{c o a l} \\
& +\left(\frac{\partial g_{d C}(j)}{\partial t}\right)_{B}+\left(\frac{\partial g_{d C}(j)}{\partial t}\right)_{a q}+\left(\frac{\partial g_{d C}(j)}{\partial t}\right)_{d i f f}
\end{aligned}
$$

Here, $g_{d C}(j)$ represent $s$ the mass density distribution functions of chemical species $g_{d S(I V)}(j), g_{d S(V I)}(j)$, $g_{d \mathrm{O}_{3}}(j), \quad g_{d \mathrm{H}_{2} \mathrm{O}_{2}}(j), g_{d \mathrm{HO}_{2}}(j), g_{d \mathrm{HCOOH}}(j), g_{d \mathrm{HCHO}}(j)$, $g_{d \mathrm{OH}}(j)$ and $g_{d \mathrm{HMSA}}(j)$ and which correspond to $\mathrm{S}(\mathrm{IV}), \mathrm{S}(\mathrm{VI}), \mathrm{O}_{3}, \mathrm{H}_{2} \mathrm{O}_{2}$, peroxyl radical $\mathrm{HO}_{2}$, total formic acid $\left(\mathrm{HCOOH}+\mathrm{HCOO}^{-}\right)$total formaldehyde $\left(\mathrm{H}_{2} \mathrm{C}(\mathrm{OH})_{2}+\mathrm{HCHO}\right)$, the hydroxyl radical $(\mathrm{OH})$, and the hydroximethanesulfonate ion $\mathrm{HMSA}\left(\left[\mathrm{HOCH}_{2} \mathrm{SO}_{3}^{1-}\right]\right)$ in the drops, respectively.

The equations for the mass density distribution functions of chemical species $\left(g_{d s C}(j)\right)$ for small drops: $g_{d s S(I V)}(j)$, $g_{d s S(V I)}(j), g_{d s \mathrm{O}_{3}}(j), g_{d s \mathrm{H}_{2} \mathrm{O}_{2}}(j), g_{d s \mathrm{HO}_{2}}(j), g_{d s \mathrm{HCOOH}}(j)$, $g_{d s \mathrm{HCHO}}(j), g_{d s \mathrm{OH}}(j)$ and $g_{d s \mathrm{HMSA}}(j)$, have the form:

$\frac{\partial g_{d s C}(j)}{\partial t}=-w \frac{\partial g_{d s C}(j)}{\partial z}-2 \frac{\alpha^{2}}{a}|w|\left[g_{d s C}(j)-g_{d s C e}(j)\right]$ 
$+\frac{2}{a} u_{a}\left[g_{d s C}(j)-g_{d s C a}(j)\right]+\frac{1}{\rho_{a}} \frac{\partial}{\partial z}\left(\rho_{a} K \frac{\partial g_{d s C}(j)}{\partial z}\right)$

$+\left(\frac{\partial g_{d s C}(j)}{\partial t}\right)_{a c t}+\left(\frac{\partial g_{d s C}(j)}{\partial t}\right)_{C E}+\left(\frac{\partial g_{d s C}(j)}{\partial t}\right)_{a q}+\left(\frac{\partial g_{d s C}(j)}{\partial t}\right)_{d i f f}$

now the coalescence, breakup terms and the effect of droplet's terminal velocity are not included.

Gas phase species evolve according to:

$$
\begin{aligned}
& \frac{\partial C_{g, i}}{\partial t}=-w \frac{\partial C_{g, i}}{\partial z}-2 \frac{\alpha^{2}}{a}|w|\left(C_{g, i}-C_{g e, i}\right)+\frac{2}{a} u_{a}\left(C_{g, i}-C_{g a, i}\right) \\
& +\frac{1}{\rho_{a}} \frac{\partial}{\partial z}\left(\rho_{a} K \frac{\partial}{\partial z} C_{g, i}\right)+\left(\frac{\partial C_{g, i}}{\partial t}\right)_{d i f f}
\end{aligned}
$$

where $\mathrm{C}_{g, i}(i=1,7)$ is the gas concentration of $\mathrm{SO}_{2}, \mathrm{O}_{3}$, $\mathrm{H}_{2} \mathrm{O}_{2}, \mathrm{HO}_{2}, \mathrm{HCOOH}, \mathrm{HCHO}$ and $\mathrm{OH}$ in the air. The gas phase rate due to the uptake to or desorption from solution droplets in the category $j$ is given by the expression,

$$
\left(\frac{\partial C_{g, i, j}}{\partial t}\right)_{d i f f}=-\left(\frac{d C_{l, i, j}}{d t}\right) M_{g} V_{d}(j) f_{d}(j)
$$

where $M_{g}$ is the molecular mass of the gas, $V_{d}(j)$ is the volume of the drops in category $j$ and $f_{d}(j)$ is the cloud number density distribution function and $\left(\frac{d C_{l, i, j}}{d t}\right)$ is calculated according to (Eq. 12). The final bulk mass transfer rate for each $i$ gas due to the uptake (desorption) is calculated by integrating (for both small droplets and drops, $73+48$ bins ) over all the categories in the form:

$$
\begin{aligned}
& \left(\frac{\partial C_{g, i}}{\partial t}\right)_{d i f f}=-\sum_{j=1}^{48}\left(\frac{d C_{l, i, j}}{d t}\right) M_{g} V_{d s}(j) f_{d s}(j) \\
& -\sum_{j=1}^{73}\left(\frac{d C_{l, i, j}}{d t}\right) M_{g} V_{d}(j) f_{d}(j)
\end{aligned}
$$

In Eq. (1-8), $t$ represents time and $\alpha^{2}$ is the coefficient for lateral eddy mixing, which is assumed to be 0.1 . The vertical eddy diffusion coefficient $K$ is considered constant and the same for all variables and assumed to be $25 \mathrm{~m}^{2} / \mathrm{s}$, and $a$ is the cloud radius that is set equal to $1000 \mathrm{~m}$ in our simulations.

\subsection{Chemistry}

2.3.1 The influence of CCN organic composition on the critical supersaturation

Following Mircea et al. (2002), we define:

(a) the classical inorganic case (CIC), assuming that the $\mathrm{CCN}$ soluble part is composed only by inorganic compounds, in particular we use $\left(\left(\mathrm{NH}_{4}\right)_{2} \mathrm{SO}_{4}\right)$.

(b) the inorganic + organic case (IOC), when the CCN composition includes inorganic and WSOC.
Because the organic composition of the $\mathrm{CCN}$ cannot be attributed to a few major species alone the organic composition to be used in numerical simulations of cloud physical and chemical processes needs some simplifications. As was pointed out by Saxena and Hildemann (1996), observations regarding the molecular composition of the watersoluble organic fraction are limited. In some studies, only approximately 5 to $20 \%$ of the total water-soluble organic carbon was resolved into specific compounds. Decesari et al. (2000), investigated aerosol and fog water samples and found that acidic compounds (mono/dicarboxylic acids) are the dominant WSOC, accounting for an average 59\% of soluble organic species.

For maritime aerosols Putaud et al. (2000) reported that dicarboxylic acids of low molecular mass (DA) represent an average $7 \%$ of the total mass while polyacidic compounds of higher molecular mass (PACC) constitute 3\% of the total mass. In rural aerosols, the fraction of DA increases up to $14 \%$.

Mircea et al. (2002) considered both CIC and IOC CCN composed of $50 \%$ by mass of soluble inorganic matter, and the remaining 50\% insoluble for the CIC, and 30\% insoluble and $20 \%$ WSOC for the IOC CCN. They parameterized the DA as an acid with a molecular mass $\mathrm{M}=100$ and number of dissociated ions $v=3$ while the polyacidic compounds of higher molecular mass (PACC) was parameterized as fulvic acid having $\mathrm{M}=732$ and $\nu=5$. The soluble inorganic part was considered to be composed by $\left(\mathrm{NH}_{4}\right)_{2} \mathrm{SO}_{4}(26 \%)$ and $\mathrm{NH}_{4} \mathrm{NO}_{3}(24 \%)$.

Putaud et al. (2000) mesaured organic, inorganic, mineral content and mass concentration of the submicron aerosol for maritime conditions. In the unperturbed marine boundary layer the aerosol average composition was $37 \%$ for non-seasalt $\mathrm{SO}_{4}^{2-}, 21 \%$ for sea salt, and $20 \%$ for organic compounds. On the other hand, Penner and Novakov (1996) reported that, in urban areas, in comparison to organic carbon, average sulfate concentrations were low, about $4.7 \%$ of total suspended particles (TSP).

Following these results, in our study we considered an intermediate fraction $(10 \%)$ of the total $\mathrm{CCN}$ non-sea-salt $\left(\left(\mathrm{NH}_{4}\right)_{2} \mathrm{SO}_{4}\right.$. This intermediate value is expected to reflect more realistically the situation near petroleum platforms, where primary emitted particles are likely to have a large fraction of the mass composed by organic material. The remaining $90 \%$ in the CIC is considered to be insoluble material (with a density of $2.5 \mathrm{~g} / \mathrm{cm}^{3}$ ), while in the IOC, $50 \%$ is considered insoluble and 40\% WSOC (see Table 1).

As pointed out by Kawamura et al. (1996), dicarboxylic acids are mostly present in particulate phase in the ambient atmosphere. Kawamura and Kaplan (1987) measured the aerosol concentrations of dicarboxylic acids in the urban atmosphere of Los Angeles. They found that oxalic acid was the dominant dicarboxylic acid followed by succinic, malonic, maleic, adipic and phtalic acidis. Yao et al. (2002) studied the PM2.5 concentrations and the size distributions 
Table 1. Critical supersaturations for aqueous solution drops containing CIC and IOC aerosols (following Mircea et al., 2002). DA is a dicarboxylic acid of low molecular mass (oxalic acid), and INS the insoluble fraction.

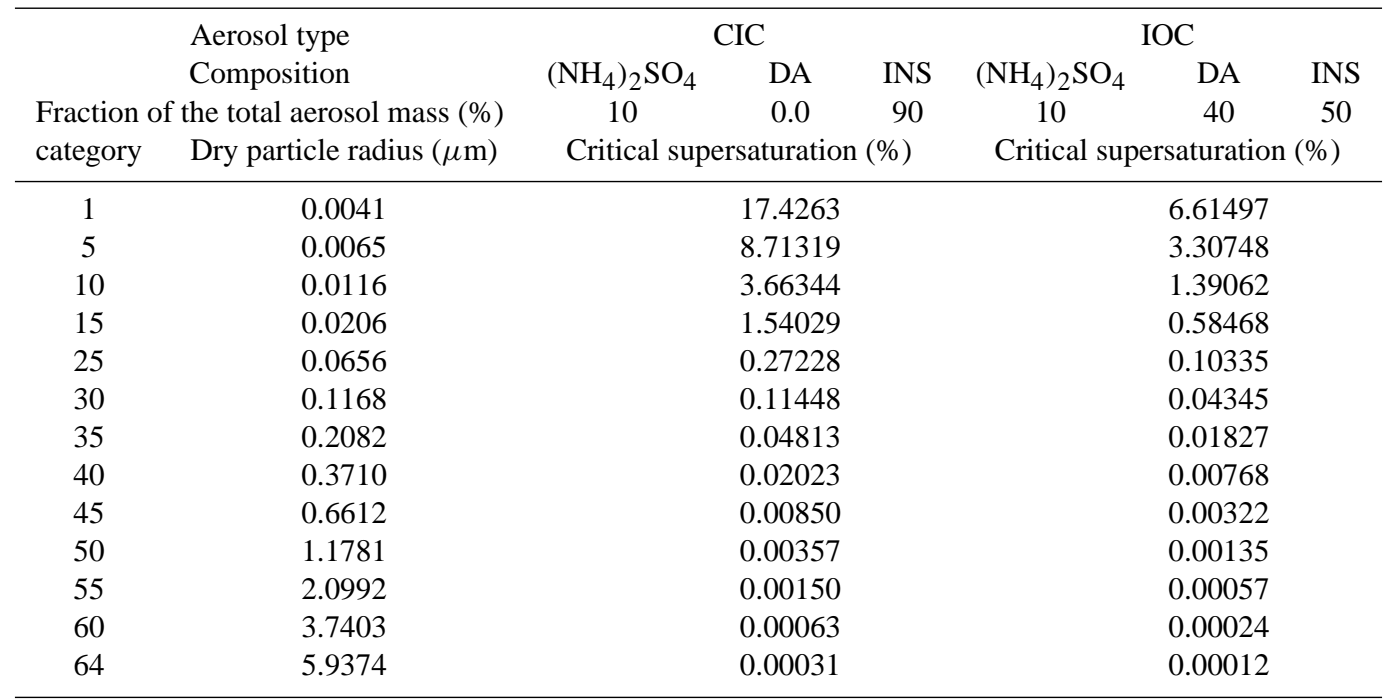

of dicarboxylic acids in Hong Kong. On average, they found that the oxalate concentration was larger than the malonate and succinate concentrations. Low molecular weight dicarboxylic acids and their salts are highly water soluble. Among these, oxalic acid is generally the most abundant (Kawamura et al., 1996). The above mentioned reasons justify our parameterization of the WSOC as oxalic acid having $\mathrm{M}=90$, and $\nu=3$.

In order to take into account the presence of WSOC in the $\mathrm{CCN}$ we used a modified form of the Köhler equation (Mircea et al., 2002):

$S=\frac{2 \sigma M_{w}}{R_{v} T \rho_{w} r}-\frac{3 \Phi_{s} M_{w}}{4 \pi \rho_{w} r^{3}} \times\left(\sum_{i \_ \text {inorg }} \frac{v_{i} m_{i}}{M_{i}}+\sum_{j \_o r g} \frac{v_{j} m_{j}}{M_{j}}\right)$

where $S$ is the supersaturation ratio, $M_{w}$ and $\rho_{W}$ are the molecular mass and density of water, $\sigma$ is the surface tension, $\Phi_{s}$ is the osmotic coefficient $\left(\Phi_{s}=1\right), R_{v}$ is the gas constant, $T$ is the temperature, and $r$ is the droplet radius. The number of dissociated ions, soluble mass and molecular mass respectively of the inorganic and organic components of CCN particles are represented by $v_{i}, m_{i}, M_{i}$ and $v_{j}, m_{j}, M_{j}$. An ideal solution is assumed $\left(\rho_{s}=\rho_{W}\right)$.

Even though Facchini et al. (1999) found a relationship for the variation of the cloud droplet surface tension $(\sigma$ in Eq. 11) as a function of dissolved organic carbon concentration, we neglect this dependency in this study.

Table 1 shows the influence of the organic compounds present in the initial $\mathrm{CCN}$, on the critical supersaturation spectrum (CSS) for 13 of the $64 \mathrm{CCN}$ bins used in our simulations. IOC CCN require lower critical supersaturation to activate than CIC CCN for the same dry radius. The smallest IOC CCN $(0.0041 \mu \mathrm{m})$ becomes activated at $6.61 \%$, while a supersaturation of $17.42 \%$ is required to activate the smallest $\mathrm{CCN}$ in the CIC. On average for all dry CCN sizes the critical supersaturation in the IOC is a about a factor of 3 smaller than in the CIC.

\subsubsection{Uptake and desorption}

The uptake and desorption of the following gas-phase species: sulfur dioxide, $\left(\mathrm{SO}_{2}\right)$; hydrogen peroxide, $\left(\mathrm{H}_{2} \mathrm{O}_{2}\right)$; peroxyl radical $\left(\mathrm{HO}_{2}\right)$; ozone, $\left(\mathrm{O}_{3}\right)$; hydroxyl radical, $(\mathrm{OH})$; formaldehyde, $(\mathrm{HCHO})$; formic acid, $(\mathrm{HCOOH})$ for a drop of radius " $r$ " was implemented by means of a quasi analytical solution of the equation:

$\frac{d C_{l, i, j}}{d t}=\frac{3 D_{g, i} f_{g}}{r^{2}(j)}\left(C_{g \infty, i}-\frac{C_{l, i, j}}{K_{h, i}^{*} R T}\right)$

where $C_{g \infty, i}(\mathrm{i}=1,7)$ is the concentration in the gas phase. $C_{l, i, j}(i=1,7)$ is the aqueous phase concentration in category $j$ of the corresponding aqueous phase species: $\mathrm{S}(\mathrm{IV})$, $\mathrm{O}_{3}, \mathrm{H}_{2} \mathrm{O}_{2}, \mathrm{HO}_{2}$, total formic acid $\left(\mathrm{HCOOH}+\mathrm{HCOO}^{-}\right)$, total formaldehyde $\left(\mathrm{H}_{2} \mathrm{C}(\mathrm{OH})_{2}+\mathrm{HCHO}\right)$ and the hydroxyl radical $(\mathrm{OH}) . D_{g, i}$ is the diffusion coefficient for gas species $i, f_{g}$ the ventilation coefficient for water vapor in air, $K_{h, i}^{*}$ the modified Henry's law coefficient for gas species $i$, that depends on $\mathrm{pH}, R_{v}$ the universal gas constant and $T$ the temperature.

The reaction with $\mathrm{O}_{3}$ plays an important role both as a sink of gas-phase $\mathrm{SO}_{2}$ and as a source of cloudwater acidification as long as the $\mathrm{pH}$ of the droplets exceeds about 4 . On the other hand, $\mathrm{H}_{2} \mathrm{O}_{2}$ is very soluble in water and under typical ambient conditions its aqueous phase concentration is approximately six orders of magnitude higher than that of dissolved ozone. 
At every time step in the simulation the aqueous concentration $C_{l, i}$, is calculated by using the analytical expression

$C_{l, i, j}(t)=\left(C_{l 0, i, j}-K_{h, i}^{*} R T C_{g \infty, i}\right) e^{\left(\left(-3 D_{g, i} / r^{2}(j) K_{h, i}^{*} R T\right) t\right)}+$ $K_{h, i}^{*} R T C_{g \infty, i}$

and the method described in detail in AR2002. The gas phase concentrations are updated at every time step using the aqueous phase concentrations calculated in Eq. (12).

\subsubsection{Aqueous phase chemistry}

The equilibrium aqueous phase chemistry and dissociation constants for inorganic and organic species are listed in Tables 2 and 3.

The $\mathrm{S}(\mathrm{IV})$ is oxidated by $\mathrm{H}_{2} \mathrm{O}_{2}, \mathrm{O}_{3}$ and $(\mathrm{OH})_{a q}$ in order to generate $\mathrm{S}(\mathrm{VI})$. The production of formic acid from hydrated formaldehyde, that is oxidized by the hydroxyl radical in the aqueous phase $(\mathrm{OH})_{a q}$, is also calculated. $\mathrm{HSO}_{3}^{-}$reacts with disolved formaldehyde to produce the hydroximethanesulfonate ion (HMSA), that is a member of the S(IV) family. The $\mathrm{HO}_{2}$ cycle is also included in the simulations. The aqueous phase photochemistry of the hydrogen peroxide at a constant rate is also considered (equinox conditions with a cloud transmissivity factor of 0.5 ).

The Livermore Solver for Ordinary Differential Equations (DLSODE) was used to solve equations listed in Tables 2 and 3. The method solves the initial-value problem for stiff or nonstiff systems of first-order ODE's. The disadvantage of this method, like other Gear (1971) type solvers, is that it needs to solve large matrices of partial derivatives, hence limiting its use in three dimensional or large scale models (Barth et al., 2003).

\subsection{4 $\mathrm{pH}$ calculation}

The resulting acidity defined by $\mathrm{pH}=-\log \left[\mathrm{H}^{+}\right]$is derived from the electroneutrality condition that in the general case is:

$\sum \gamma_{i} n_{i}=0$

where $n_{i}$ is the concentration of an ion of charge $\gamma_{i}$. In particular, for the situation studied here:

$$
\begin{aligned}
& {\left[\mathrm{NH}_{4}^{+}\right]+\left[\mathrm{H}^{+}\right]=\left[\mathrm{OH}^{-}\right]+\left[\mathrm{HSO}_{3}^{-}\right]+2\left[\mathrm{SO}_{3}^{2-}\right]+\left[\mathrm{HSO}_{4}^{-}\right]} \\
& +2\left[\mathrm{SO}_{4}^{2-}\right]+\left[\mathrm{HCOO}^{-}\right]+\left[\mathrm{HD}^{-}\right]+2\left[\mathrm{D}^{2-}\right] \\
& +\left[\mathrm{HOCH}_{2} \mathrm{SO}_{3}^{-}\right]+\left[\mathrm{O}_{2}^{-}\right]
\end{aligned}
$$

A polynomial equation in $\left[\mathrm{H}^{+}\right]$is then obtained in the form:

$$
\begin{aligned}
& {\left[\mathrm{NH}_{4}^{+}\right]+\left[\mathrm{H}^{+}\right]=\frac{\mathrm{k}_{\mathrm{w}}}{\left[\mathrm{H}^{+}\right]}+[\mathrm{S}(\mathrm{IV})] \frac{\left(\mathrm{K}_{1}\left[\mathrm{H}^{+}\right]+2 \mathrm{~K}_{1} \mathrm{~K}_{2}\right)}{\left(\left[\mathrm{H}^{+}\right]^{2}+\mathrm{K}_{1}\left[\mathrm{H}^{+}\right]+\mathrm{K}_{1} \mathrm{~K}_{2}\right)}} \\
& +[\mathrm{S}(\mathrm{VI})] \frac{\left(2 \mathrm{~K}_{3}+\left[\mathrm{H}^{+}\right]\right)}{\left(\mathrm{K}_{3}+\left[\mathrm{H}^{+}\right]\right)}+[\mathrm{HCOOH}] \frac{\mathrm{K}_{\mathrm{HCOOH}}}{\left(\left[\mathrm{H}^{+}\right]+\mathrm{K}_{\mathrm{HCOOH}}\right)}
\end{aligned}
$$

$$
\begin{aligned}
& +\left[\mathrm{H}_{2} \mathrm{D}\right] \frac{\left(\mathrm{K}_{\mathrm{D} 1}\left[\mathrm{H}^{+}\right]+2 \mathrm{~K}_{\mathrm{D} 1} \mathrm{~K}_{\mathrm{D} 2}\right)}{\left(\left[\mathrm{H}^{+}\right]^{2}+\mathrm{K}_{\mathrm{D} 1}\left[\mathrm{H}^{+}\right]+\mathrm{K}_{\mathrm{D} 1} \mathrm{~K}_{\mathrm{D} 2}\right)}+\left[\mathrm{HOCH}_{2} \mathrm{SO}_{3}^{-}\right] \\
& +\left[\mathrm{HO}_{2}\right] \frac{\mathrm{K}_{\mathrm{HO}_{2}}}{\left(\left[\mathrm{H}^{+}\right]+\mathrm{K}_{\mathrm{HO}_{2}}\right)}
\end{aligned}
$$

In this equation, $K_{1}, K_{2}$ and $K_{3}$ and $k_{w}$ are the dissociation equilibrium constants for the $\mathrm{S}(\mathrm{IV}), \mathrm{S}(\mathrm{VI})$ and water respectively, and $K_{\mathrm{HCOOH} 1}, K_{D 1}, K_{D 2}$, and $K_{\mathrm{HO}_{2}}$ are the constants for the formic, oxalic acids and $\mathrm{HO}_{2}$ respectively. As we pointed out in the introduction, the role of WSOC in the $\mathrm{pH}$ spectrum of precipitation, is beyond the scope of this study and wasn't included in the analysis. Thus, the $\mathrm{pH}$ in our simulations is calculated for each drop category for the CIC case, and Eq. (15) without the term for the oxalic acid was actually used.

\section{Initial conditions}

\subsection{CCN distributions}

Simulations were performed with two maritime distributions for the classic inorganic (CIC) and the inorganic+organic cases (IOC). Each distribution consists of a superposition of two log-normal CCN distributions with the same parameters as in AR2002.

Although Hoppel et al. (1990) reported total concentrations above $200 \mathrm{~cm}^{-3}$ in the Atlantic Ocean, the total CCN concentration in our simulations is $100 \mathrm{~cm}^{-3}$, typical of maritime conditions. The shape of the distribution is discussed carefully in a previous paper (Alfonso and Raga, 2002).

When the concentration was increased, a simulated cloud with an unrealistic long lifetime was obtained. A similar situation was reported by Takahashi (1976), using the same dynamics, when he observed an overestimation of cloud lifetime for the continental case. With the same dynamics, a cloud of an infinite lifetime was obtained when a small autoconversion coefficient was set in the parameterization for the autoconversion (Ogura and Takahashi, 1971). Because of that, an increase in the $\mathrm{CCN}$ concentrations due to the anthropogenic activity was not considered in our simulations. Therefore, the total CCN concentration is $100 \mathrm{~cm}^{-3}$ in the contaminated case. The accumulation mode concentration of the CCN spectra was set equal to $50 \mathrm{~cm}^{-3}$.

\subsection{Initial vertical distributions of thermodynamic parame-} ters and gaseous species.

Chameides (1984) set very low initial concentrations $\left(10^{-4} \mathrm{ppb}\right)$ of formic acid. For realistic atmospheric conditions, initial $\mathrm{HCOOH}_{(g)}$ concentrations are often higher, between 0.03-1.7 ppb; (Chebbi and Carlier, 1996) and are close to those of $\mathrm{HCHO}_{(g)}$. Granby et al. (1997) reported urban winter mean concentrations of $0.80 \pm 0.30 \mathrm{ppb}$ for formic 
Table 2a. Equilibrium reactions (Henry's Law Equilibria).

\begin{tabular}{llll}
\hline Reaction & $\left.\mathrm{K}_{H, 298(\text { Matm }}^{-1}\right)$ & $\Delta \mathrm{H}_{298} / R$ & Reference \\
\hline$\left(\mathrm{SO}_{2}\right)_{g} \leftrightarrow\left(\mathrm{SO}_{2}\right)_{a q}$ & 1.2 & -3135 & Hoffmann\&Calvert (1985) \\
$\left(\mathrm{O}_{3}\right)_{g} \leftrightarrow\left(\mathrm{O}_{3}\right)_{a q}$ & $1.15 \times 10^{-2}$ & -2560 & NBS \\
$\left(\mathrm{H}_{2} \mathrm{O}_{2}\right)_{g} \leftrightarrow\left(\mathrm{H}_{2} \mathrm{O}_{2}\right)_{a q}$ & $9.7 \times 10^{4}$ & -6600 & NBS \\
$\left(\mathrm{HO}_{2}\right)_{g} \leftrightarrow\left(\mathrm{HO}_{2}\right)_{a q}$ & $9 \times 10^{3}$ & -6600 & Bielski (1978) \\
$(\mathrm{OH})_{g} \leftrightarrow(\mathrm{OH})_{a q}$ & 25 & -5200 & Klanning et al. (1985) \\
$(\mathrm{HCHO})_{g} \leftrightarrow\left(\mathrm{CH}{ }_{2}(\mathrm{OH})_{2}\right)_{a q}$ & $7 \times 10^{3}$ & -6425 & NBS \\
$(\mathrm{HCOOH})_{g} \leftrightarrow(\mathrm{HCOOH})_{a q}$ & $3.7 \times 10^{3}$ & -5700 & NBS \\
\hline
\end{tabular}

Table 2b. Dissociation constants.

\begin{tabular}{llll}
\hline Reaction & $\mathrm{K}_{H, 298}(\mathrm{M})$ & $\Delta \mathrm{H}_{298} / R$ & Reference \\
\hline$\left(\mathrm{SO}_{2}\right)_{a q} \leftrightarrow \mathrm{HSO}_{3}^{-}+\mathrm{H}^{+}$ & $1.7 \times 10^{-2}$ & -2090 & NBS \\
$\mathrm{HSO}_{3}^{-} \leftrightarrow \mathrm{H}^{+}+\mathrm{SO}_{3}^{2-}$ & $6 \times 10^{-8}$ & -1120 & NBS \\
$\left(\mathrm{HO}_{2}\right)_{a q} \leftrightarrow \mathrm{H}^{+}+\mathrm{O}_{2}^{-}$ & $2 \times 10^{-5}$ & 0 & Bielski (1978) \\
$(\mathrm{HCOOH})_{a q} \leftrightarrow \mathrm{HCOO}^{-}+\mathrm{H}^{+}$ & $1.8 \times 10^{-4}$ & 1500 & Helas et al. (1992) \\
\hline
\end{tabular}

acid and $2.6 \pm 0.7 \mathrm{ppb}$ for formaldehyde, while at a semi rural site concentrations were $0.6 \pm 0.3$ and $0.9 \pm 0.5$, respectively.

Arlander et al. (1990) reported mesaurements of the background levels of trace organic species in the remote marine troposphere. For the northern hemisphere Pacific Ocean the mean formic acid concentration was $0.80 \pm 0.30 \mathrm{ppb}$, while in the southern hemisphere was $0.22 \pm 0.13 \mathrm{ppb}$. For the northern hemisphere Indian Ocean the mean concentration was $0.75 \pm 0.24 \mathrm{ppb}$. In general formic acid gas phase concentrations in maritime zones are in the range between 0.03$1.7 \mathrm{ppb}$ and 0.1-13.4 ppb for the formaldehyde (Arlander et al., 1990 and references therein). In our study, a 1 ppb initial concentration at the surface for both formic acid and formaldehyde was chosen.

Table 4 presents the initial concentrations at the surface for all the gaseous species. Hidroxyl radical concentration has a large variability during the day, but in this study was set equal to $5 \times 10^{-4} \mathrm{ppb}$ following Ridley et al. (1992). A high background concentration of $\mathrm{SO}_{2}(20 \mathrm{ppb})$ is assumed to simulate anthropogenic emissions from the petroleum platforms following Ramos (1997). All gas concentrations are assumed to decrease exponentially with height as in AR2002.

The initial sounding corresponds to the city of Veracruz, located on the coast of the Gulf of Mexico (see AR2002). A small updraft is imposed to start convection in the layer below $2 \mathrm{~km}$, with a maximun value of $1 \mathrm{~ms}^{-1}$ at a height of $1 \mathrm{~km}$. The duration of the simulations is $80 \mathrm{~min}$.
Table 2c. Dissociation constants.

\begin{tabular}{llll}
\hline Acid & $\mathrm{K}_{1}(\mathrm{M})$ & $\mathrm{K}_{2}(\mathrm{M})$ & Reference \\
\hline Oxalic & $5.9 \times 10^{-2}$ & $6.4 \times 10^{-5}$ & Kawamura et al. (1996) \\
\hline
\end{tabular}

Table 2d. Aqueous-phase species.

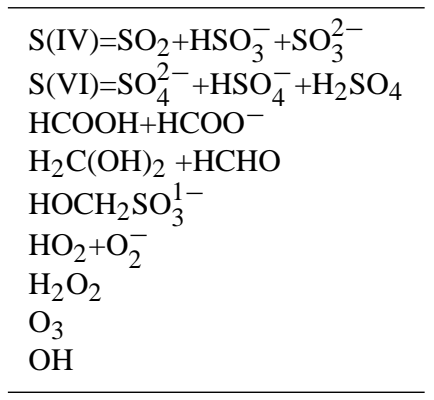

\section{Results}

\subsection{Sensitivity to CCN composition}

The evolution of dynamical and microphysical cloud characteristics was discussed in detailed in AR2002. We do not include some tests regarding cloud parameters as cloud radius here. However, some sensitivity tests to prescribed cloud parameters (i.e. cloud radius) can be found in Alfonso et al. (1998).

A summary of the results obtained for the CIC and IOC simulations is presented in Table 5. Both experiments show 
Table 3a. Aqueous phase reactions. Oxygen-Hydrogen Chemistry.

\begin{tabular}{lll}
\hline Reaction & Kinetic constant $\left(\mathrm{M}^{-n+1} \mathrm{~s}^{-1}\right)$ & Reference \\
\hline $\mathrm{H}_{2} \mathrm{O}_{2}+\mathrm{h} \nu \rightarrow 2 \mathrm{OH}$ & $1.4 \times 10^{-5}$ & Graedel and Weschler (1981) \\
$\mathrm{O}_{3}+\mathrm{h} \nu+\mathrm{H}_{2} \mathrm{O} \rightarrow \mathrm{H}_{2} \mathrm{O}_{2}+\mathrm{O}_{2}$ & $6.0 \times 10^{-5}$ & Graedel and Weschler (1981) \\
$\mathrm{OH}+\mathrm{O}_{2}^{-} \rightarrow \mathrm{OH}^{-}+\mathrm{O}_{2}$ & $1.0 \times 10^{10}$ & Sehested et al. (1968) \\
$\mathrm{OH}+\mathrm{H}_{2} \mathrm{O}_{2} \rightarrow \mathrm{H}_{2} \mathrm{O}+\mathrm{HO}_{2}$ & $2.7 \times 10^{7}$ & Christensen et al. (1982) \\
$\mathrm{HO}_{2}+\mathrm{HO}_{2} \rightarrow \mathrm{H}_{2} \mathrm{O}_{2}+\mathrm{O}_{2}$ & $8.6 \times 10^{5}$ & Bielski (1978) \\
$\mathrm{HO}_{2}+\mathrm{O}_{2}^{-} \rightarrow \mathrm{H}_{2} \mathrm{O}_{2}+\mathrm{O}_{2}+\mathrm{OH}^{-}$ & $1.0 \times 10^{8}$ & Bielski (1978) \\
$\mathrm{OH}+\mathrm{O}_{3} \rightarrow \mathrm{HO}_{2}+\mathrm{O}_{2}$ & $2 \times 10^{9}$ & Staehelin et al. (1984) \\
$\mathrm{O}_{2}^{-}+\mathrm{O}_{3}+\mathrm{H}_{2} \mathrm{O} \rightarrow \mathrm{OH}+2 \mathrm{O}_{2}+\mathrm{OH}^{-}$ & $1.5 \times 10^{9}$ & Sehested et al. (1983) \\
$\mathrm{OH}+\mathrm{OH} \rightarrow \mathrm{H}_{2} \mathrm{O}_{2}$ & $5.2 \times 10^{9}$ & Lelieveld and Crutzen (1991) \\
\hline
\end{tabular}

Table 3b. Aqueous phase reactions. Organic Chemistry.

\begin{tabular}{lll}
\hline Reaction & Kinetic constant $\left(\mathrm{M}^{-n+1} \mathrm{~s}^{-1}\right)$ & Reference \\
\hline $\mathrm{H}_{2} \mathrm{C}(\mathrm{OH})_{2}+\mathrm{OH} \rightarrow \mathrm{HCOOH}+\mathrm{HO}_{2}+\mathrm{H}_{2} \mathrm{O}$ & $2 \times 10^{9}$ & Bothe and Schulte-Frohlinde (1980) \\
$\mathrm{HCOOH}+\mathrm{OH} \rightarrow \mathrm{H}_{2} \mathrm{O}+\mathrm{CO}_{2}+\mathrm{HO}_{2}$ & $2 \times 10^{8}$ & Scholes and Wilson (1967) \\
$\mathrm{HCOO}^{-}+\mathrm{OH} \rightarrow \mathrm{HO}_{2}+\mathrm{CO}_{2}+\mathrm{OH}^{-}$ & $2.5 \times 10^{9}$ & Anbar and Neta (1967) \\
\hline
\end{tabular}

Table 3c. Aqueous phase reactions. Sulfur Chemistry.

\begin{tabular}{lll}
\hline Reaction & Kinetic constant $\left(\mathrm{M}^{-n+1} \mathrm{~s}^{-1}\right)$ & Reference \\
\hline $\mathrm{S}(\mathrm{IV})+\mathrm{H}_{2} \mathrm{O}_{2} \rightarrow \mathrm{S}(\mathrm{VI})+\mathrm{H}_{2} \mathrm{O}$ & $7.45 \times 10^{7}$ & McArdle and Hoffmann (1983) \\
$\mathrm{HSO}_{3}^{-}+\mathrm{OH} \rightarrow \mathrm{OH}^{-}+2 \mathrm{H}^{+}+\mathrm{SO}_{4}^{2-}+\mathrm{SO}_{4}^{-}$ & $4.5 \times 10^{9}$ & Huie and Neta (1984) \\
$\mathrm{S}(\mathrm{IV})+\mathrm{O}_{3} \rightarrow \mathrm{S}(\mathrm{VI})+\mathrm{O}_{2}$ & $2.4 \times 10^{4}$ & Hoffmann and Clavert (1985) \\
\hline
\end{tabular}

Table 4. Gas-phase chemical species and initial concentrations at the surface.

\begin{tabular}{ll}
\hline Gas-Phase Species & Initial concentrations at the surface. $(\mathrm{ppb})$ \\
\hline $\mathrm{SO}_{2}$ (High ambient conc.) & 20 \\
$\mathrm{SO}_{2}$ (Low ambient conc.) & 1 \\
$\mathrm{HO}_{2}$ & $1 \times 10^{-2}$ \\
$\mathrm{H}_{2} \mathrm{O}_{2}$ & 1 \\
$\mathrm{O}_{3}$ & 100 \\
$\mathrm{OH}$ & $5 \times 10^{-4}$ \\
$\mathrm{HCHO}$ & 1 \\
$\mathrm{HCOOH}$ & 1 \\
\hline
\end{tabular}

cloud top at about $6 \mathrm{~km}$. The differences in maximum vertical velocity are not significant, but the maxima were obtained at different times in the evolution. The more pronounced differences between the two runs are evident in the droplet concentration, presented in Fig. 1, as a function of height after $44 \mathrm{~min}$ of simulation. In general, the droplet concentration is smaller in the CIC by $35 \%$ and these differences have an effect in the development of precipitation.
In our study, the dicarboxylic acid is treated as it is fully dissociated at activation. Nevertheless, some simulations were performed in order to test the sensitivity of our results to dissociation constant of oxalic acid. The IOC curve of Fig. 1 was recalculated considering that the oxalic acid in the Köhler equation was not fully dissociated (the dissociation constant was changed to close to 1). A new curve was obtained (IOC_1), that is situated in between the CIC and IOC curves. Obviously a smaller droplet concentration than the IOC was obtained, as can be observed in Fig. 1. Then, for this case (IOC_1), the fraction of WSOC was increased, and the fraction of insoluble material was decreased and new calculations were performed. We found that relative fractions of $85 \%$ for the WSOC and $5 \%$ for insoluble material were needed in order to get a curve close to the original IOC curve. The remaining calculations in our study were made with the choice of Mircea et al. (2002) for the dissociation constant, and with $40 \%$ of WSOC and $50 \%$ of insoluble material.

As can be observed in Table 5, in the IOC the maximum concentration of droplets is higher than the initial CCN concentration. This is a result of the sedimentation of droplets in an eulerian framework. In this case we have droplets that 
Table 5. Results obtained for the CIC and IOC experiments.

\begin{tabular}{lll}
\hline Experiment & CIC & IOC \\
\hline Max vertical velocity $\left(\mathrm{m} \mathrm{s}^{-1}\right)$ & 10.03 & 10.33 \\
Time (min) and height $(\mathrm{m})$ & 43,3600 & 47,3800 \\
Maximum concentration (droplets + raindrops) $\left(\mathrm{cm}^{-3}\right)$ & 74.6 & 124.4 \\
Mean diameter $(\mu \mathrm{m})$ & 10.39 & 9.21 \\
Time (min) and height $(\mathrm{m})$ & 31,2000 & 30,2000 \\
Precipitation reaching ground $\left(1 \mathrm{~g} \mathrm{~kg}^{-1}\right)$ after time $(\mathrm{min})$ & 60 & 63 \\
Maximum supersaturation $(\%)$ & 3.4 & 2.9 \\
Time (min) and height $(\mathrm{m})$ & 50,4500 & 53,4900 \\
\hline
\end{tabular}

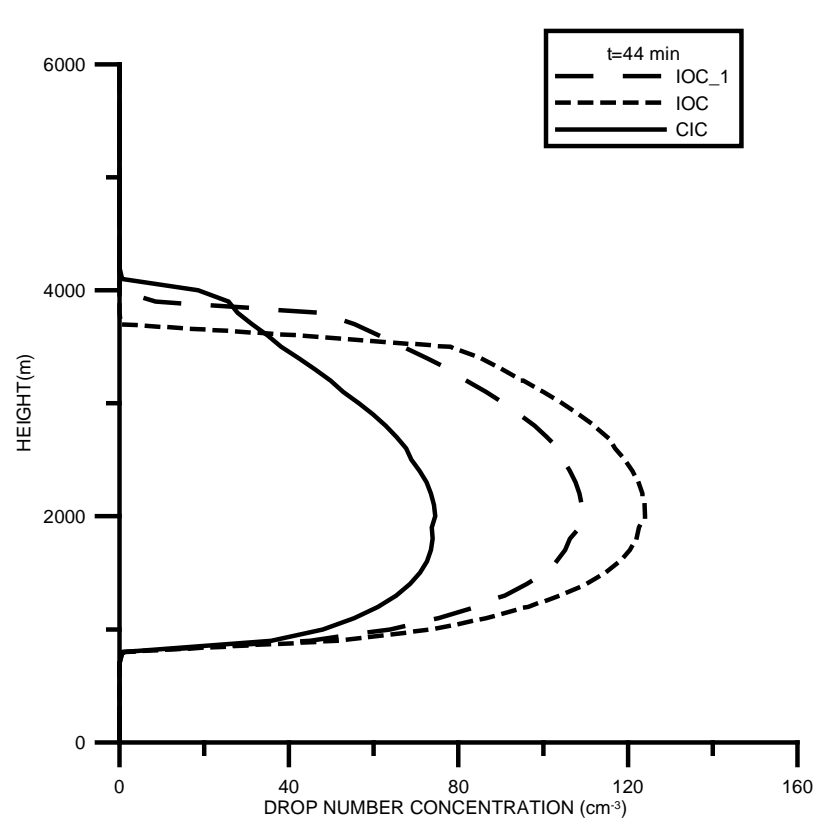

Fig. 1. Droplet number concentration $\left(\mathrm{cm}^{-3}\right)$ as a function of height for the classical inorganic case (CIC), the inorganic+organic case (IOC) and the inorganic+organic case with not fully dissociated dicarboxylic acid (IOC_1) after 44 min of simulation.

were activated at a different altitude within the cloud and have reached the $2000 \mathrm{~m}$ level because of their terminal velocity. Another point is the presence of CCN that are activated as soon they enter the cloud from the side (it is cylindrical, and there is an incloud radial velocity in the lower part). Precipitation concentration of $1 \mathrm{~g} \mathrm{~kg}^{-1}$ reached the ground after 60 minutes of simulation in the CIC, and after $63 \mathrm{~min}$ in the IOC. In our simulations, we only tested the influence of the initial CCN concentration and chemical composition in the precipitation development. We did not change any other parameters of the $\mathrm{CCN}$ distribution like the dispersion and the mean radius.

The maximum supersaturations are larger in the CIC simulation, due to the smaller maximum droplet concentrations ( $\mathrm{S}=3.4 \%$ in the CIC vs $2.9 \%$ in the IOC).

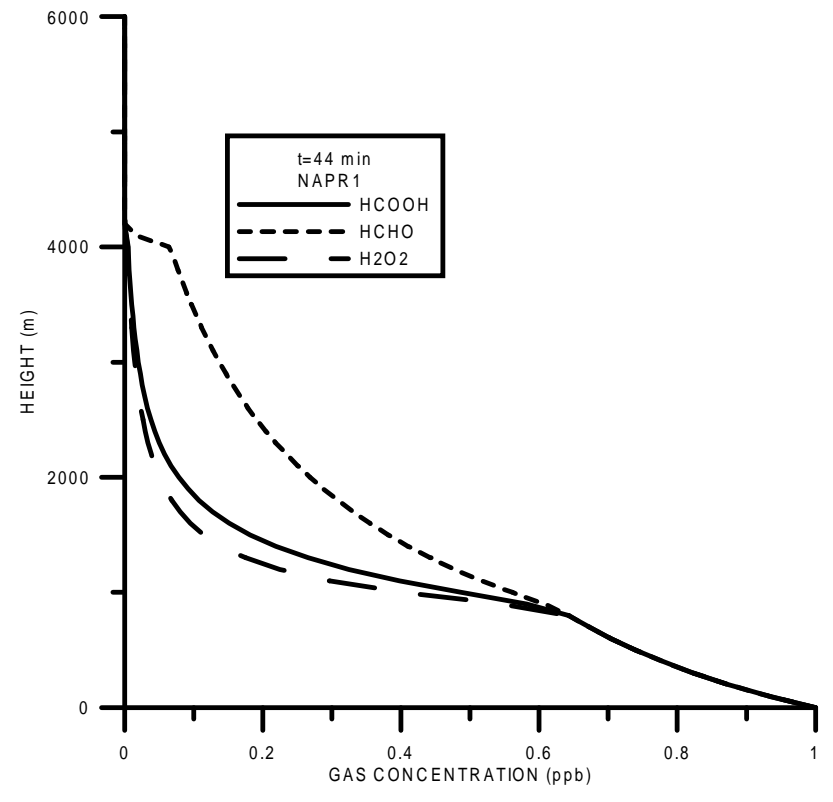

Fig. 2. Gas phase concentrations (ppb) of $\mathrm{H}_{2} \mathrm{O}_{2}, \mathrm{HCHO}$ and $\mathrm{HCOOH}$ as a function of height after 44 min of simulation, for the case with no aqueous phase oxidation.

\subsection{Calculations of $\mathrm{pH}$}

\subsubsection{High ambient $\mathrm{SO}_{2}$ concentration (20 ppb)}

Four simulations (summarized in Table 6) were performed in order to test the influence of the aqueous phase chemistry and the initial concentration of formic acid in the $\mathrm{pH}$ droplet spectra, the CCN composition on all the simulations is the CIC composition $\left(\left(\mathrm{NH}_{4}\right)_{2} \mathrm{SO}_{4}\right)$. These simulations are summarized in Table 6.

\section{Cases with no aqueous-phase oxidation (NAPR1 and NAPR0)}

Since no aqueous phase oxidation is ocurring, the process that causes the increase in droplet's acidity in the 


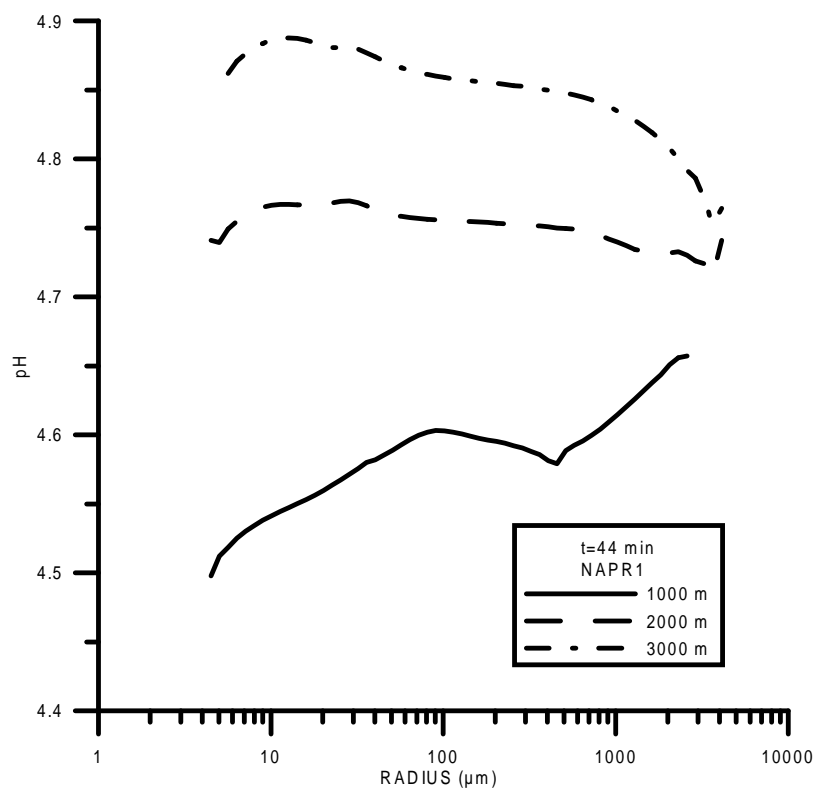

Fig. 3. $\mathrm{pH}$ at three different incloud levels after $44 \mathrm{~min}$ of simulation, for the case with no aqueous phase oxidation and an initial gas-phase concentration of formic acid of 1 pbb (NAPR1).

NAPR1 and NAPR0 simulations is the direct transfer of acidic $\mathrm{CCN}$ and gases to droplets (the diffusion of $\mathrm{SO}_{2}$, and the diffusion and dissociation of $\mathrm{HCOOH})$. The vertical variation of the gas concentration in air for $\mathrm{HCHO}, \mathrm{HCOOH}$, $\mathrm{H}_{2} \mathrm{O}_{2}$ is displayed in Fig. 2 after 44 min of simulation. Due to the high solubility constant for $\mathrm{H}_{2} \mathrm{O}_{2}$, its gas concentrations in air are lowest since it diffuses faster than $\mathrm{HCHO}$ and $\mathrm{HCOOH}$.

The $\mathrm{pH}$ spectra obtained at three different incloud levels are displayed in Fig. 3. In the NAPR1 case droplets become less acidic with increasing height because they tend to be in equilibrium with the environmental gas concentrations, that decrease with height. As a result, aqueous S(IV) and $\mathrm{HCOOH}$ concentration decrease with height and the $\mathrm{pH}$ increases. Droplets larger than $200 \mu \mathrm{m}$ at 2000 and $3000 \mathrm{~m}$ are mainly produced by collisions of numerous small drops that have scavenged $\mathrm{SO}_{2}$ and $\mathrm{HCOOH}$ according to Henry's law at lower levels where gas concentrations are larger. They are more acidic because they desorb $\mathrm{SO}_{2}$ and $\mathrm{HCOOH}$ less efficiently than smaller droplets and they have larger concentrations than equilibrium $\mathrm{S}(\mathrm{IV})$ and $(\mathrm{HCOOH})_{a q}$ concentrations at that height. At cloud base $(1000 \mathrm{~m})$ smaller droplets are in equilibrium with gas concentrations and are more acidic than larger drops.

An aditional simulation (NAPR0) with no initial concentration of $(\mathrm{HCOOH})_{g}$ was performed to test the influence of the gas phase concentration of formic acid in the droplets acidity. The differences between the two simulations are shown in Fig. 4 for a height of $2000 \mathrm{~m}$. A lowering of the $\mathrm{pH}$ by $0.1 \mathrm{pH}$ units (about $2 \%$ reduction) is observed for every

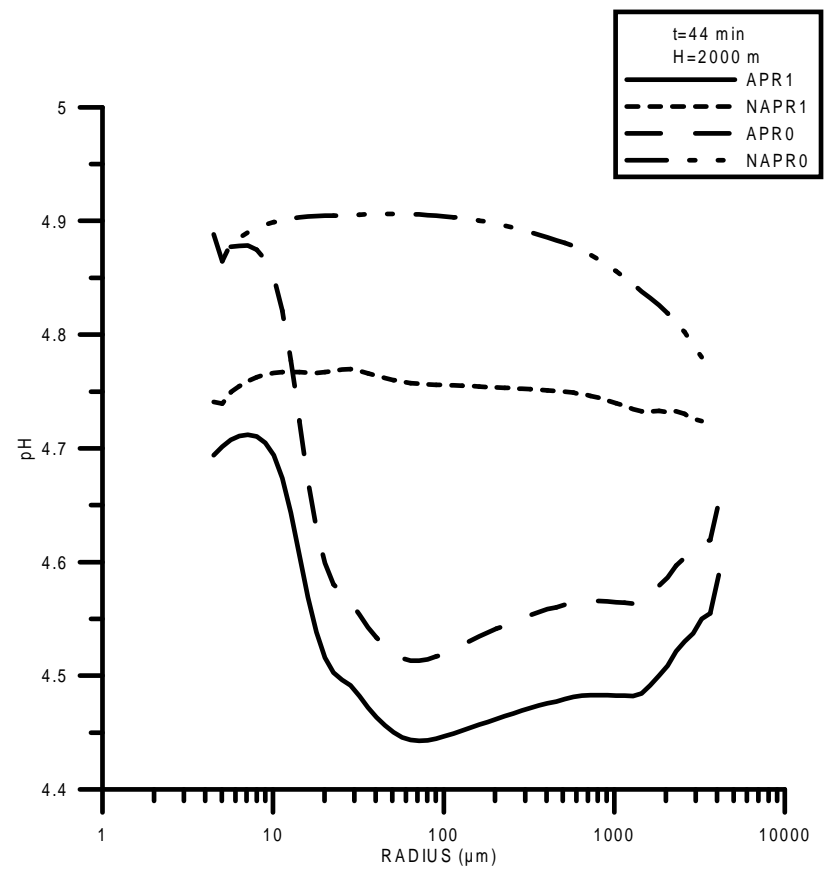

Fig. 4. $\mathrm{pH}$ at $2000 \mathrm{~m}$ for the cases with aqueous phase oxidation and an initial gas-phase concentration of formic acid of 0 and $1 \mathrm{ppb}$ respectively (APR0, APR1) and no aqueous-phase oxidation (NAPR0, NAPR1), after 44 min of simulation.

drop category when gas phase formic acid is present (compare curves marked as NAPR0 and NAPR1).

The contribution of monocarboxylic and dicarboxylic acids to bulk rain acidity was estimated by Kawamura et al. (1996) from experimental data. They reported that, although nitric and sulfuric acid are the principal contributors to $\mathrm{H}^{+}$ion concentration in acid rain, organic acids lower the $\mathrm{pH}$ of rainwater between 0.1 and $1.9 \mathrm{pH}$ units. Our results considering high $\mathrm{SO}_{2}$ ambient concentration are consistent with their lower estimate of $\mathrm{pH}$ change due to organic acids.

\section{Cases with aqueous-phase oxidation (APR1 and APR0)}

In the APR1 simulation, chemical reactions decrease the concentration of dissolved $\mathrm{SO}_{2}, \mathrm{H}_{2} \mathrm{O}_{2}, \mathrm{O}_{3}, \mathrm{HCHO}$ and $\mathrm{OH}$ to produce $\mathrm{S}(\mathrm{VI}), \mathrm{HCOOH}, \mathrm{HMSA}$, enhance cloud water acidity and perturb the equilibrium aqueous phase concentrations of the mentioned species. Consequently, a gas phase adjustment takes place enhancing the uptake of species that are depleted in the aqueous phase.

A significant reduction in the gas-phase concentrations compared to the NAPR 1 case is observed, as for example for the $\mathrm{H}_{2} \mathrm{O}_{2}, \mathrm{SO}_{2}$ and $\mathrm{OH}$ (see Figs. 5, 6 and 7 ) after 44 min of simulation. The reason for the decrease in the gas phase concentractions at a height of $4000 \mathrm{~m}$ is the exponential decrease with altitude of the gas phase concentrations of all species in the initial conditions (see Figs. 6 and 7). As a result of cloud 
Table 6. Simulations performed for high (20 ppb) and low (1 ppb) ambient $\mathrm{SO}_{2}$ concentrations.

\begin{tabular}{|c|c|c|}
\hline & \multirow{2}{*}{$\begin{array}{l}\text { No aqueous phase oxidation } \\
\text { Initial }(\mathrm{HCOOH}) g \text { concentration at the earth's surface } \\
\text { (ppb) }\end{array}$} & \multirow{2}{*}{$\begin{array}{l}\text { With aqueous phase oxidation } \\
\text { Initial }(\mathrm{HCOOH})_{g} \text { gas concentration at the earth's } \\
\text { surface }(\mathrm{ppb})\end{array}$} \\
\hline & & \\
\hline & 0 & 0 \\
\hline Aerosol composition & \multicolumn{2}{|l|}{ CIC: $\left(\mathrm{NH}_{4}\right)_{2} \mathrm{SO}_{4}(10 \%$ fraction of the total aerosol mass $)$} \\
\hline Simulation & NAPR1 NAPR0 & APR1 \\
\hline
\end{tabular}

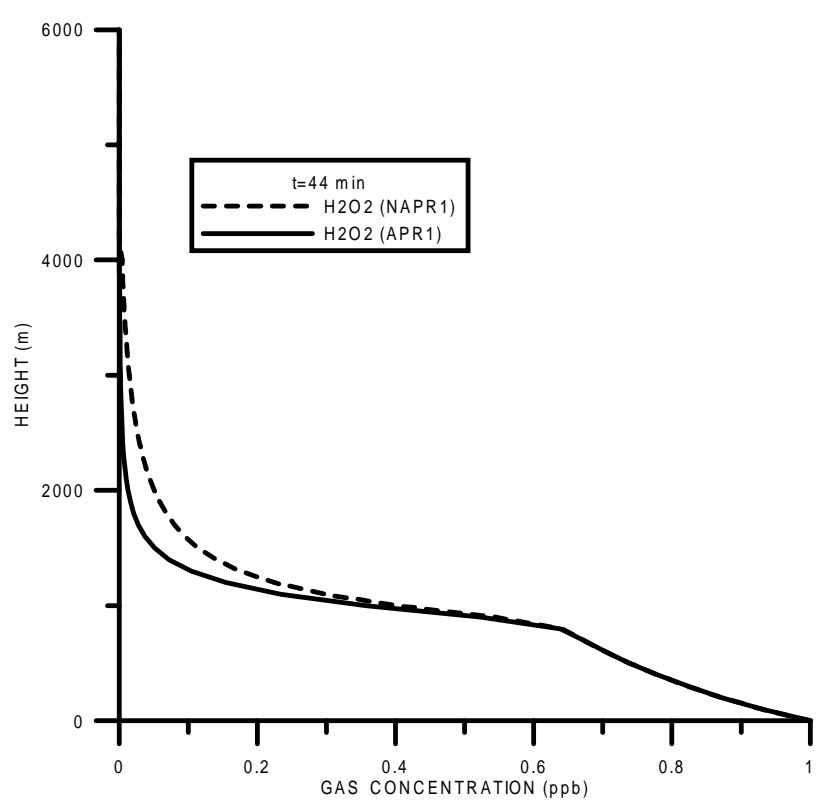

Fig. 5. Gas-phase $\mathrm{H}_{2} \mathrm{O}_{2}$ concentration (ppb) as a function of height for the cases with aqueous and no aqueous-phase oxidation, an initial formic acid gas-phase concentration of $1 \mathrm{ppb}$, and high (20 ppb) $\mathrm{SO}_{2}$ ambient concentration (APR1, NAPR1), after 44 min of simulation.

development, the concentrations of all species increases, because they are advected by the updraft, but the initial concentrations at every level of the cloud were smaller. The $4000 \mathrm{~m}$ level in Figs. 6 and 7 corresponds to the cloud top. Above that level, the gas phase concentrations are very low because they correspond to the initial conditions, that prescribed an exponential decrease with height.

A comparison between $\mathrm{pH}$ spectrum obtained for the NAPR1 and APR1 cases is given in Fig. 4, where a pH reduction for the APR 1 case up to 0.5 units is observed for a model time of $44 \mathrm{~min}$ at $2000 \mathrm{~m}$.

There are some differences in the spectral behaviour of the aqueous phase species. As $\mathrm{SO}_{2}$ is taken up by cloud water as $\mathrm{S}(\mathrm{IV})$ and is converted to $\mathrm{S}(\mathrm{VI})$ by oxidizing gases in the aqueous phase $\left(\mathrm{H}_{2} \mathrm{O}_{2}, \mathrm{O}_{3}\right.$ and $\left.\mathrm{OH}\right)$, the production of acid from $\mathrm{SO}_{2}$ takes some time, and is most concentrated

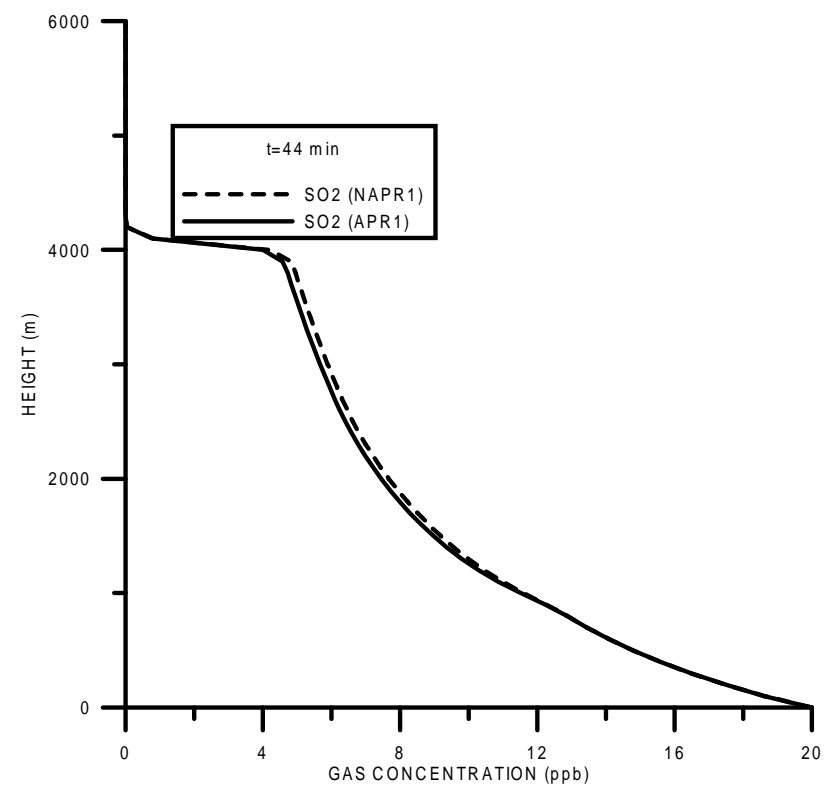

Fig. 6. Gas-phase $\mathrm{SO}_{2}$ concentration (ppb) as a function of height for the cases with aqueous and no aqueous-phase oxidation, an initial formic acid gas-phase concentration of $1 \mathrm{ppb}$, and high (20 ppb) $\mathrm{SO}_{2}$ ambient concentration (APR1, NAPR1), after 44 min of simulation.

in the largest, oldest drops, that have lived the longest time. On the other hand, the scavenged $\mathrm{SO}_{2}$ gas is redistributed to the large end of the spectrum as a consequence of the collision coalescence process. This can be deduced from Fig. 8, where in general smaller S(IV) concentrations are observed for droplets in the interval $80-4000 \mu \mathrm{m}$, as a result of $\mathrm{S}$ (IV) oxidation. On the other hand, the S(VI) is more concentrated in large drops in comparison with small droplets, because of the microphysical conversion due to the collisioncoalescence process.

Because of its high solubility, the $(\mathrm{HCOOH})_{a q}$ resulting from the uptake of $(\mathrm{HCOOH})_{g}$ is confined mainly to the small drops both at cloud base $(1000 \mathrm{~m})$ and at $2000 \mathrm{~m}$ at 44 min (see Fig. 9). The reduction of the aqueous phase concentration with height is a result of the exponential decrease in environmental gas concentrations. Then the gas is 


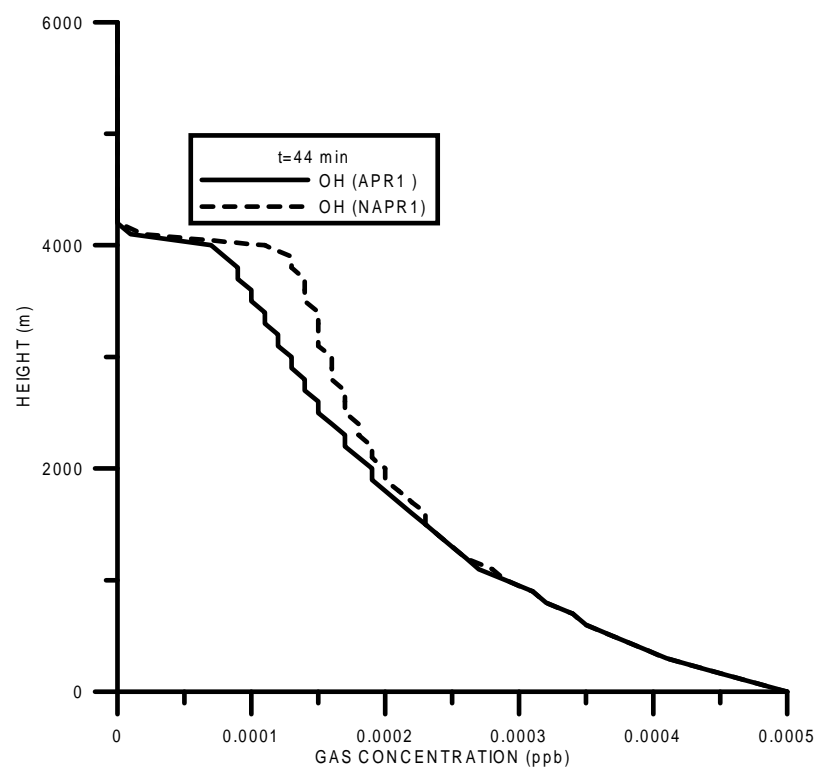

Fig. 7. Same as Fig. 6 but for $\mathrm{OH}$ concentration.

transferred to the large end of the spectrum (500-4000 $\mu \mathrm{m})$ by droplet collisions and coalescence. The aqueous phase concentration is larger at the small end of the spectrum for the case with aqueous phase reactions (APR1). Aqueous phase reactions can explain higher formic acid concentrations at the small end of the spectrum in APR1 than in NAPR1 case. In both cases, $\mathrm{HCOOH}$ uptake takes place. Thus only aqueous phase oxidation of formaldehyde can explain the differences, since the oxidation of $\mathrm{HCHO}$ is more important at the small end when gas uptake is more efficient.

A similar situation was explored by Wurzler et al. (1995) for only inorganic acids, indicating that the scavenging behaviour of nitrate and of sulfate is significant different, because nitric acid in cloud water is formed directly on uptake of $\mathrm{HNO}_{3}$ gas, and sulfuric acid is formed after the reaction with oxidizing agents such as $\mathrm{H}_{2} \mathrm{O}_{2}$. They found also that nitrate resulting from uptake of $\mathrm{HNO}_{3}$ is confined mainly to small drops, whereas sulfate is most concentrated at the large end of the spectrum. Although the $(\mathrm{HCOOH})_{a q}$ is also destroyed by the reaction with the $(\mathrm{OH})_{a q}$, in this study we observe a behaviour similar to the one discussed by Wurzler et al. (1995).

Even though the production of sulfuric acid is the most important factor in generating droplet's acidity, there is a contribution due to the diffusion and generation of formic acid in the droplets. As seen in Fig. 4, there is a reduction in $\mathrm{pH}$ (between 0.1 and $0.15 \mathrm{pH}$ units) in the entire spectrum.

\subsubsection{Low ambient $\mathrm{SO}_{2}$ concentration (1 ppb)}

Again four simulations were performed in order to test the importance of the uptake and formic acid production in drop acidity, listed in Table 6.

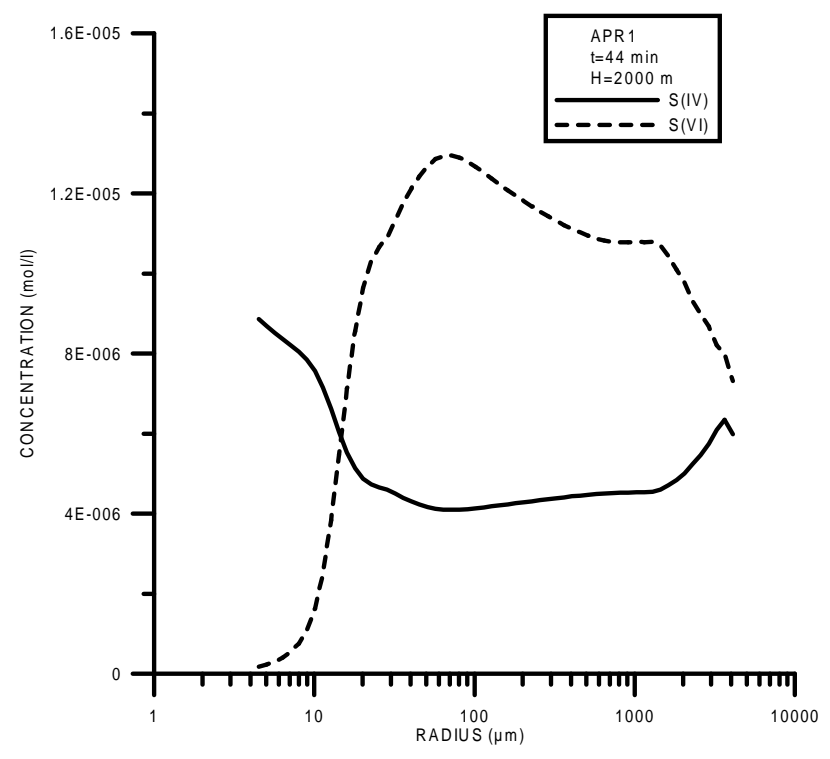

Fig. 8. S(IV) and S(VI) aqueous phase concentrations at $2000 \mathrm{~m}$ for the case with aqueous-phase oxidation, an initial formic acid gas-phase concentration of $1 \mathrm{ppb}$ and high $(20 \mathrm{ppb}) \mathrm{SO}_{2}$ ambient concentration (APR1), after 44 min of simulation.

\section{Cases with no aqueous-phase oxidation (NAPR1 and NAPR0)}

In the NAPR1 simulation, the diffusion and dissociation of $\mathrm{HCOOH}$ is very important in generating the acidity of the droplets, as seen in Fig. 10. The $\mathrm{pH}$ variation is large, and a decrease from a $\mathrm{pH}$ in the 5.2-5.5 range for the NAPR 0 to a $\mathrm{pH}$ of 5 for the NAPR1 is observed. The presence of $\mathrm{HCOOH}$ increases the acidity drastically (NAPR1), specially for smaller drops that have a more efficient uptake. The acidity increases with radius for the NAPR0 due to higher concentrations of S(IV) at the large end. This large concentrations are a consequence of the microphysical conversion due to collision-coalescence process.

\section{Cases with aqueous-phase oxidation (APR1 and APR0)}

In the APR0 simulation, the results show an increase of the acidity at the large end, because $\mathrm{S}(\mathrm{VI})$ is more concentrated in large drops as a result of the microphysical conversion due to coalescence. For the APR1 case, less pronounced increase with radius is observed, due to the uptake of $\mathrm{HCOOH}$, that is confined mainly to the small drops. In the high ambient $\mathrm{SO}_{2}$ concentration case (20 ppb) , the behaviour of the $\mathrm{pH}$ spectrum at the small end was modulated by the S(IV) and the $\mathrm{pH}$ decreased from 4.9 to 4.5 approximately. In the low ambient $\mathrm{SO}_{2}$ concentration case, there is an increase in acidity due to the $\mathrm{HCOOH}$ 


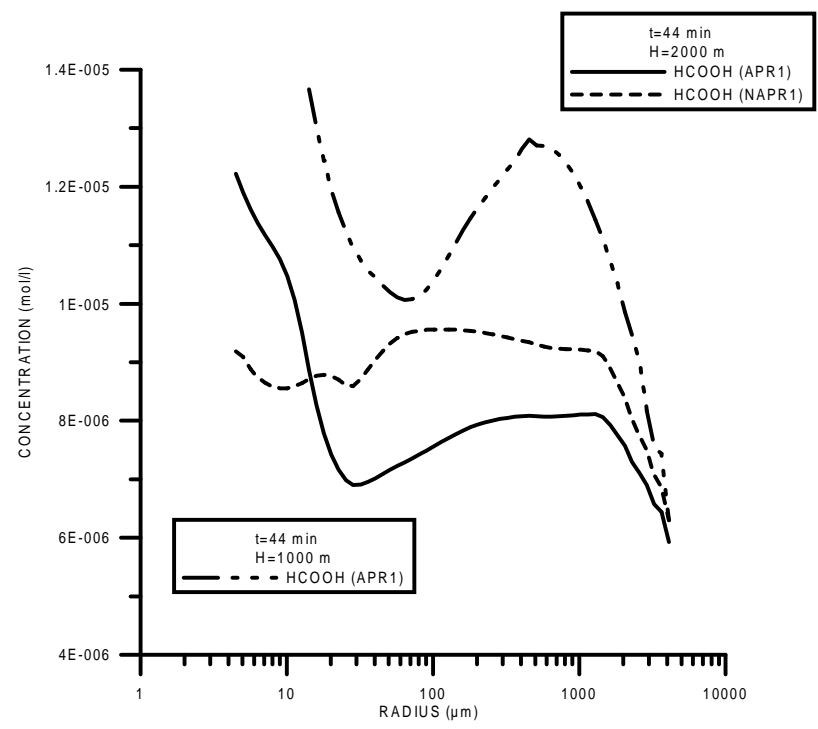

Fig. 9. HCOOH aqueous phase concentration at two different incloud levels (1000 and $2000 \mathrm{~m}$ ), for the cases with aqueous phase oxidation, and no aqueous phase oxidation, an initial formic acid gas-phase concentration of $1 \mathrm{ppb}$ and high $(20 \mathrm{ppb}) \mathrm{SO}_{2}$ ambient concentration (APR1, NAPR1), after 44 min of simulation.

uptake (from 0.2 to $0.5 \mathrm{pH}$ units). Therefore, in cases where $\mathrm{HCOOH}$ and $\mathrm{SO}_{2}$ have similar gaseous concentrations, the resulting acidity is clearly affected by the uptake and production of the organic acid.

\section{Conclusions}

This study constitutes a first attemp to estimate the contribution of organic compounds emitted by oil platforms on the development of precipitation acidity in the southern region of Gulf of Mexico. The microphysical-chemical cloud model reported in AR2002 was used to test the influence of WSOC CCN composition, solubility, and background inorganic+organic gas concentrations in the development of cloud and precipitation, and in the $\mathrm{pH}$ spectral evolution. In our previous study, primary emitted particles were assumed to have a large fraction $(90 \%)$ composed of non-soluble material. In the present study we consider that $40 \%$ of the total mass consists of WSOC (represented by oxalic acid).

The conclusions can be summarized as follows:

a) Considering the presence of WSOC in the $\mathrm{CCN}$ :

- The differences in total droplet concentrations between the CIC and IOC were significant, with lower droplet concentrations for the CIC and an earlier development of precipitation.

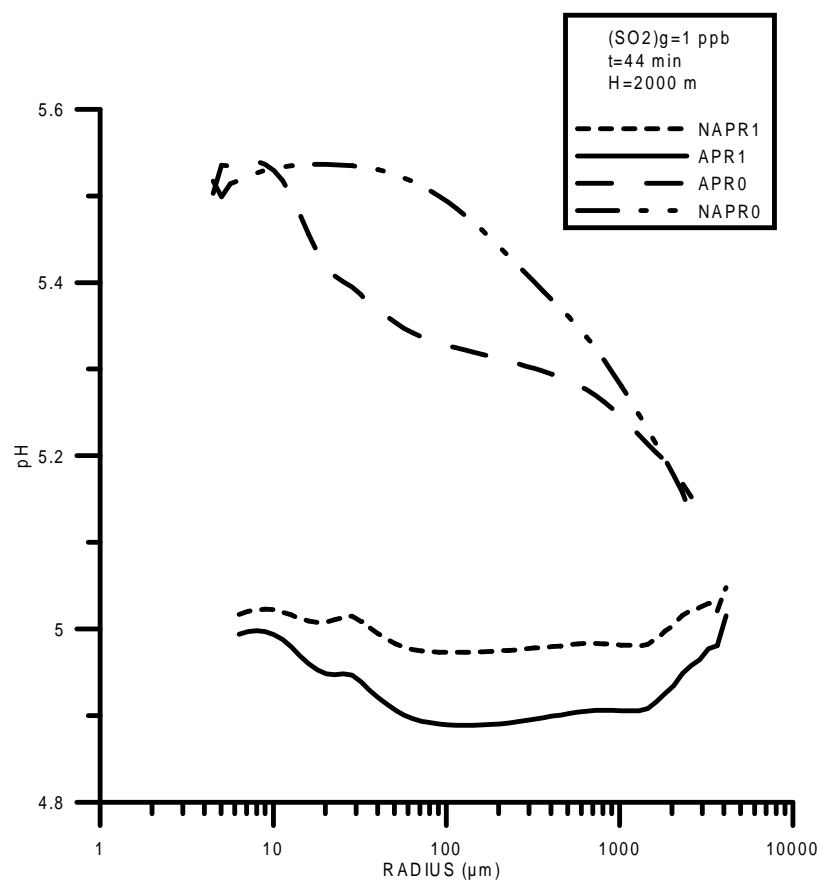

Fig. 10. $\mathrm{pH}$ at $2000 \mathrm{~m}$ for the cases with aqueous phase oxidation and an initial gas-phase concentration of formic acid of 0 and $1 \mathrm{ppb}$ respectively (APR0, APR1) and no aqueous-phase oxidation (NAPR0, NAPR1), and a low ambient $\mathrm{SO}_{2}$ concentration (1 ppb), after 44 min of simulation.

- The presence of DA in CCN reduces the critical supersaturation by a factor of 3 .

b) Considering the impact of formic acid in the final $\mathrm{pH}$ of rain:

- When no aqueous phase oxidation is allowed, dissolved species in droplets tend to be in equilibrium with the environmental gas concentrations, that are assumed to decrease with height in this study. Larger droplets (formed by collisions and coalescence of smaller ones) have higher concentrations than equilibrium $\mathrm{S}(\mathrm{IV})$ and $(\mathrm{HCOOH})_{a q}$ concentrations at upper cloud levels. Larger droplets desorb $\mathrm{SO}_{2}$ and $\mathrm{HCOOH}$ less efficiently than smaller ones. The result is an increase in the acidity at the large end of the spectrum. A reduction of the $\mathrm{pH}$ in the range from 0.05 to $0.15 \mathrm{pH}$ units was observed due to the diffusion of $\mathrm{HCOOH}$.

- The uptake of $\mathrm{HCOOH}$ is confined mainly to the small drops, due to its high solubility, with formic acid formed directly in the cloud water from the dissolved gas.

- The depletion of S(IV) by the oxidation reactions with $\mathrm{H}_{2} \mathrm{O}_{2}, \mathrm{O}_{3}$ and $\mathrm{OH}$ is observed and its concentration decreases with droplet size at upper levels.

- The reaction of S(IV) with the oxidizing agents $\left(\mathrm{H}_{2} \mathrm{O}_{2}\right.$, $\mathrm{O}_{3}$ and $\mathrm{OH}$ ) generates $\mathrm{S}(\mathrm{VI})$ and it is most concentrated 
in the largest, oldest drops, that have had more time for reaction, and because of the microphysical conversion by collision-coalescence.

- In the high ambient $\mathrm{SO}_{2}$ concentration case, a reduction in $\mathrm{pH}$ (in the range from 0.05 to $0.15 \mathrm{pH}$ units) was observed due to diffusion and aqueous phase production of $\mathrm{HCOOH}$ in the case with aqueous phase oxidation. This reduction is less pronounced at the large end of the spectrum, with oldest droplets that have produced more $(\mathrm{HCOOH})_{a q}$ from hydrated formaldehyde.

- The small reductions in the $\mathrm{pH}$ due to diffusion and generation of formic acid in the aqueous-phase are associated with the high ambient (20 ppb) $\mathrm{SO}_{2}$ concentration.

- A more pronounced increase in the acidity is observed (from 0.2 to $0.5 \mathrm{pH}$ units) up to $10 \%$ as a result of the uptake and production of formic acid in the low (1 ppb) $\mathrm{SO}_{2}$ concentration case

- When ambient gaseous concentration of $\mathrm{SO}_{2}$ and $\mathrm{HCOOH}$ are comparable, the importance of formic acid in determining the $\mathrm{pH}$ is clearly observed.

Acknowledgements. This study was partially funded through grants from Conacyt (\#32528) and (\#33319) and DGEP. The authors would like to thank Drs. Sasha Madronich and Mary Barth from NCAR and Dr. Mireya Moya from UNAM, for useful suggestions and discussions.

Edited by: A. Laaksonen

\section{References}

Alfonso, L. A., Martínez, D., and Pérez, C. A.: Numerical simulations of tropical convective clouds over Cuba using a onedimensional and time dependent model, Atmos. Res., 47-48, 343-354, 1998.

Alfonso, L. and Raga, G. B.: Estimating the impact of natural and anthropogenic emissions on cloud chemistry, Part I. Sulfur cycle, Atmos. Res., 62, 33-55, 2002.

Arlander, D. W., Cronin, D. R., Farmer, J. C., Menzia, F. A., and Westberg, H. H.: Gaseous oxygenated hydrocarbons in the remote marine troposphere, J. Geophys. Res., 95, D10, 16391$16403,1990$.

Anbar, M. and Neta, P.: A compilation of specific bimolecular rate constants for the reactions of hydrated electrons. Hydrogen atoms and hydroxyl radicals with inorganic and organic compounds in aqueous solutions, Int. J. Appl. Radiat. Isotopes, 18, 493-523, 1967.

Asai, T. and Kasahara, A.: A theoretical study of compensating downward motions associated with cumulus clouds, J. Atmos. Sci., 24, 487-496, 1967.

Barth, M. C., Sillman, S., Hudman, R., Jacobson, M. Z., Kim, C.-H., Monod, A., and Liang, J.: Summary of the cloud chemistry modeling intercomparison: Photochemical box model simulation, J. Geophys. Res., 108, D7, AAC 5-1, AAC 5-19, 10.1029/2002JD002673, 2003.
Berry, E.: Cloud droplet growth by collection, J. Atmos. Sci., 24, 688-701, 1967.

Bielski, B. H. J.: Reevaluation of the spectral and kinetic properties of $\mathrm{HO}_{2}$ and $\mathrm{O}_{2}^{-}$free radicals, Photochem. Photobiol., 28, 645649, 1978.

Bothe, E. and Schulte-Frohlinde, D.: Reaction of dihydroxymethyl radical with molecular oxygen in aqueous solution, Anorg. Chem. Org. Chem., 35, 1035-1039, 1980.

Chameides, W. L.: The photochemistry of a remote marine stratiform cloud, J. Geophys. Res., 89, 4739-4755, 1984.

Chebbi, A. and Carlier, P.: Carboxylic acids in the troposphere, occurrence, sources, and sinks: A review, Atmos. Environ., 30, 4233-4249, 1996.

Corrigan, C. E. and Novakov, T.: Cloud condensation nucleus activity of organic compounds: a laboratory study, Atmos. Environ., 33, 2661-2668, 1999.

Christensen, H., Sehested, K., and Corfitzen, H.: Reaction of hydroxyl radicals with hydrogen peroxide at ambient and elevated tempeartures, J. Phys., 77, 1111-1116, 1982.

Cruz, C. N. and Pandis, S. N.: A study of the ability of pure secondary organic aerosol to act as cloud condensation nuclei, Atmos. Environ., 31, 2205-2214, 1997.

Decesari, S., Facchini, M. C., Fuzzi, S., Tagliavini, E.: Characterization of water soluble organic compounds in atmospheric aerosol: a new approach, J. Geophys. Res., 105, 1481-1489, 2000.

Facchini, M. C., Mircea, M., Fuzzi, S., Charlson, R. J.: Cloud albedo enhancement by surface-active organic solutes in growing droplets, Nature, 401, 257-259, 1999.

Feingold, G. and Chuang, P. Y.: Analysis of the influence of film forming compounds on dropletgrowth: implications for cloud microphysical processes and climate, J. Atmos. Sci., 59, 20062018, 2002.

Gear, C. W.: Numerical Initial Value Problems in Ordinary Differential equations, Prentice Hall, Englewood Cliffs, NJ, 1971.

Graedel, T. E. and Weschler, C. J.: Chemistry within aqueous atmospheric aerosols and Raindrops, Rev. Geophys., 19, 505-539, 1981.

Granby, K., Christensen, C. C., and Lohse, C.: Urban and semirural observations of carboxylic acids and Carbonyls, Atmos. Environ., 31, 1403-1415, 1997.

Hegg, D. A., Gao, S., and Jonsson, H.: Measurements of selected dicarboxylic acids in marine cloud water, Atmos. Res., 62, 1-10, 2002.

Helas, G., Andreae, M. O., and Hartmann, W. R.: Behavior of atmospheric formic and acetic acid in the presence of hydrometeors, J. Atmos. Chem., 15, 101-115, 1992.

Hoffmann, M. R. and Calvert, J.G.: Chemical transformation Modules for Eulerian Acid Deposition Models, Volume 2, The Aqueous-Phase Chemistry, EPA/600/3-85/017. U.S. Environmental Protection Agency, Research Triangle Park, NC, 1985.

Hoppel, W. A., Fitzgerald, J. W., Frick, G. M., and Larson, R.E.: Aerosol size distributions and optical properties found in the maritime boundary layer over the Atlantic Ocean, J. Geophys. Res., 95, 3659-3686, 1990.

Huie, R. E. and Neta, P.: Chemical behaviour of $\mathrm{SO}_{3}^{-}$and $\mathrm{SO}_{5}^{-}$ radicals in solution, J. Phys. Chem., 88, 5665-5669, 1984.

Kawamura, K. and Kaplan, I. R.: Motor exhaust emissions as primary sources for dicarboxylic acids in Los Angeles ambient air, 
Envir. Sci. Technol., 21, 105-110, 1987.

Kawamura, K., Steinberg, S., and Kaplan, I. R.: Concentrations of monocarboxylic and dicarboxylic acids and aldehydes in southern California wet precipitations: Comparison of urban and nonurban samples and compositional changes during scavenging, Atmos. Environ., 30, 1035-1052, 1996.

Klanning, U. R., Sehesfeld, K., and Holcman, J.: Standard Gibbs energy of formation of the hydroxyl radical in aqueous solution, J. Phys. Chem., 89, 760-763, 1985.

Lelieveld, J. and Crutzen, P. J.: The role of clouds in tropospheric photochemistry, J. Atmos. Chem., 2, 229-267, 1991.

Likens, G. E., Edgerton, E. S., and Galloway, J. N.: The composition and deposition of organic carbon in precipitation, Tellus, 35B, 16-24, 1983.

Löflund, M., Kasper-Giebl, A., Schuster, B., Giebl, H., Hitzenberger, R., and Puxbaum, H.: Formic, acetic, oxalic, malonic and succinic acid concentrations and their contribution to organic carbon in cloud water, Atmos. Environ., 36, 1553-1558, 2002.

McArdle, J. V. and Hoffmann, M. R.: Kinetic and mechanisms of the oxidation of aquated sulfur dioxide by hydrogen peroxyde al low pH, J. Phys. Chem., 87, 5425-5429, 1983.

Mircea, M., Facchini, M. M., Decesari, S., Fuzzi, S., and Charlson, R. J.: The influence of organic aerosol component on CCN supersaturation spectra for different aerosol types, Tellus, 54B, 74-81, 2002.

National Bureau of Standards: Selected values of chemical thermodynamic properties, 1, N.B.S. Tech. Note, 270-1, 124 pp., 1965.

Novakov, T. and Penner, J. E.: Large contribution of organic aerosols to cloud-condensation-nuclei Concentrations, Nature, 365, 823-826, 1993.

Ogura, Y. and Takahashi, T.: Numerical simulation of the life cycle of a thunderstorm cell, Mon. Wea. Rev., 98, 895-911, 1971.

Penner, J. and Novakov, T.: Carbonaceous particles in the atmosphere: A historical perspective to the Fifth International Conference on Carbonaceous Particles in the Atmosphere, J. Geophys. Res., 101, D14, 19373-19378, 1996.
Putaud, J. P., Van Dingenen, R., Mangoni, M., Virkula, A., Raes, F., Maring, H., Prospero, J. M., Swielicki, E., Berg, O., Hillamo, R., and Makela, T.: Chemical clossure and assesment of the origin of the submicron aerosol in the maritime boundary layer and the free troposphere at Tenerife during ACE-2, Tellus, 52B, 141168, 2000.

Ramos, L. Y.: Evaluación de $\mathrm{SO}_{2}$ y $\mathrm{NO}_{2}$ en puntos contaminantes por la Industria Petrolera en el Estado de Tabasco, Tesis de Lic. En Química, 107 pp., 1997.

Ridley, B. A., Madronich, S., Chatfield, R. B., Walega, J. G., and Shetter, R. E.: Measurements and model simulations of the photostationary state durinf the Mauna Loa observatory photochemistry experiment: Implications for radical concentrations and ozone production and loss rates, J. Geophys. Res., 97, 10375$10388,1992$.

Saxena, P. and Hildemann, L. M.: Water soluble organics in atmospheric particles: A critical review of the literature and application of thermodynamics to identify candidate compounds, J. Atmos. Chem., 24, 57-109, 1996.

Scholes, G. and Wilson, R. L.: $\gamma$ radiolysis of aqueous thymine solutions. Determination of relative reaction rates of $\mathrm{OH}$ radicals, Trans. Faraday Soc., 63, 2982-2993, 1967.

Sehested, K., Rasmussen, O. L., and Fricke, H.: Rate constants for $\mathrm{OH}$ with $\mathrm{HO}_{2}, \mathrm{O}_{2}^{-}$, and $\mathrm{H}_{2} \mathrm{O}_{2}$ from hydrogen preoxide formation in pulse irradiated oxygenated water, J. Phys. Chem., 72, 626-631, 1968.

Sehested, K., Holeman, J., and Hart, E. J.: Rate constants and products of the reaction of $\mathrm{O}_{2}^{-}$, and $\mathrm{H}$ with ozone in aqueous solutions, Adv. Environ. Sci. Eng., 4, 1-45, 1983.

Staehelin, J., Buhler, R. E., and Hoigne, J.: Ozone decomposition in water studied by pulse radiolysis, $2 . \mathrm{OH}$ and $\mathrm{HO}_{4}$ as chain intermediates, J. Phys. Chem., 88, 5999-6004, 1984.

Takahashi, T.: Warm rain, giant nuclei and chemical balance in a numerical model, J. Atmos. Sci., 33, 269-286, 1976.

Yao, X., Fang, M., and Chan, C. K.: Size distributions and formation of dicarboxylic acids in atmospheric particles, Atmos. Environ., 36, 2099-2017, 2002.

Wurzler, S., Flossman, A. I., Pruppacher, H. R., and Schwartz, S. E.: The scavenging of nitrate by clouds and precipitation, J. Atm. Chem., 20, 259-280, 1995. 